\title{
Aufbau und Funktion des Zentralnervensystems (ZNS)
}

Copyright @ 2014 Kompetenznetz Pädiatrische Onkologie und Hämatologie

Autor: PD Dr. med. Gesche Tallen, erstellt am 24.04.2007, Redaktion: Maria

Yiallouros, Freigabe: Prof. Dr. Ursula Creutzig, Zuletzt bearbeitet: 25.06.2015

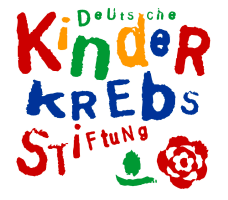




\section{Inhaltsverzeichnis}

1. Das Nervensystem des Menschen - allgemeine Einführung und Gliederung

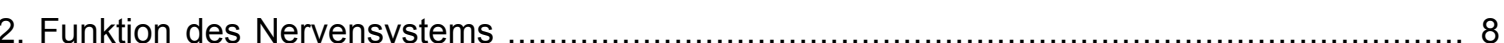

3. Das zentrale Nervensystem (Zentralnervensystem; ZNS) …....................................... 9

3.1. Aufgaben des Zentralnervensystems - Übersicht ............................................... 10

3.2. Feingeweblicher (histologischer) Aufbau des Zentralnervensystems ............................. 10

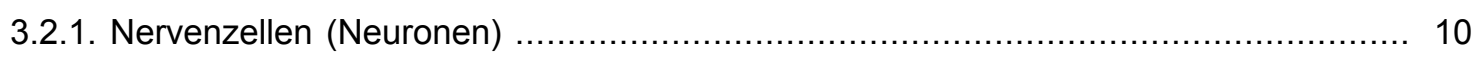

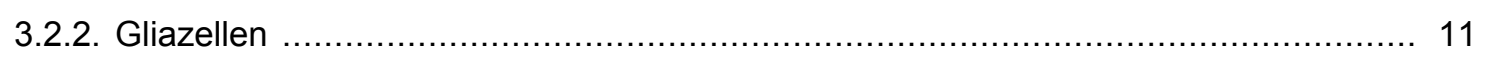

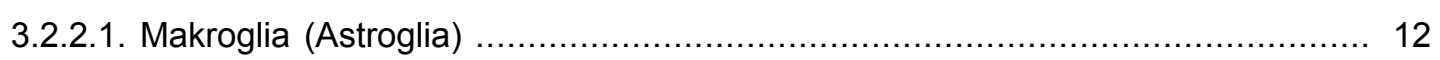

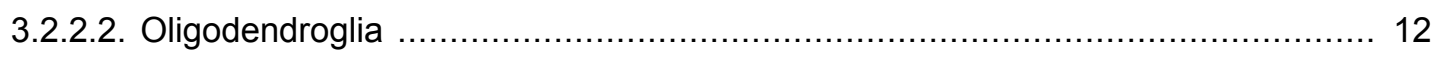

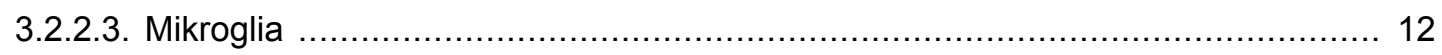

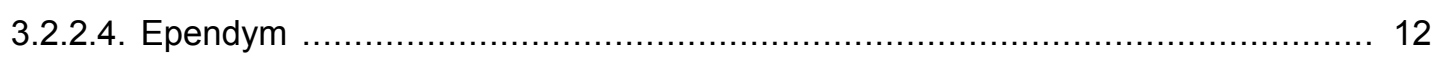

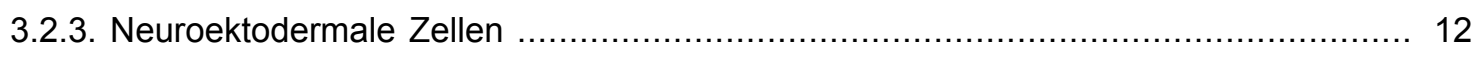

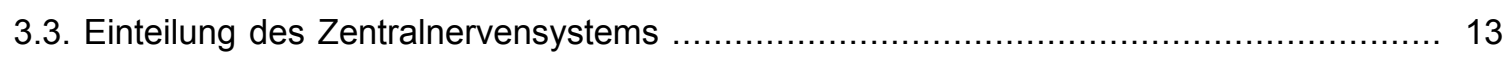

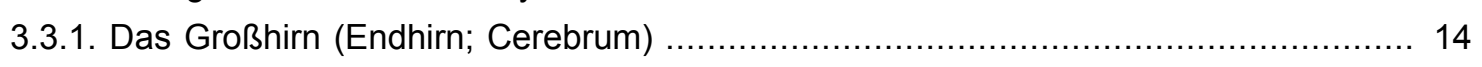

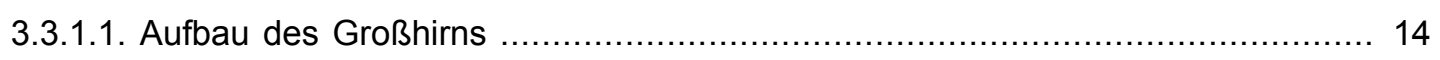

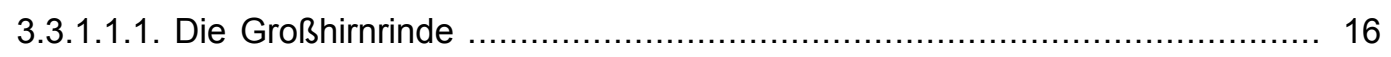

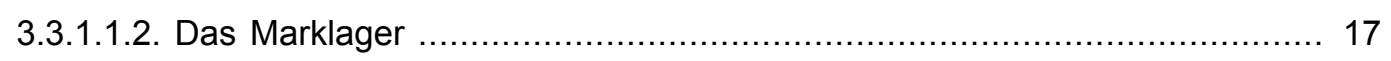

3.3.1.1.3. Nervenzellkerne (Basalganglien/Stammganglien) im

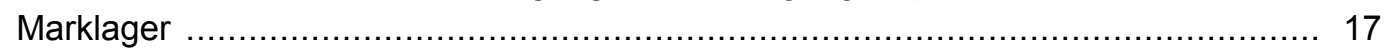

3.3.1.2. Funktionen des Großhirns .............................................................. 18

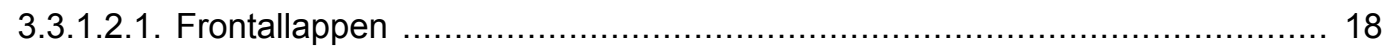

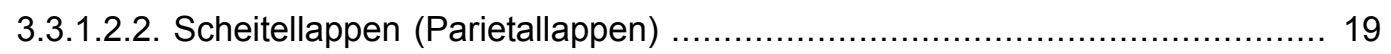

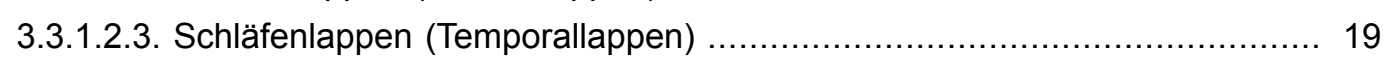

3.3.1.2.4. Hinterhauptslappen (Okzipitallappen) ......................................... 20

3.3.1.2.5. Stammganglien (Basalganglien) im Marklager .................................. 20

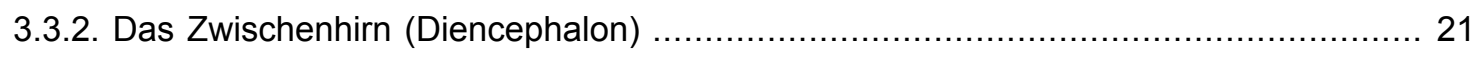

3.3.2.1. Aufbau und Funktion des Zwischenhirns ................................................ 21

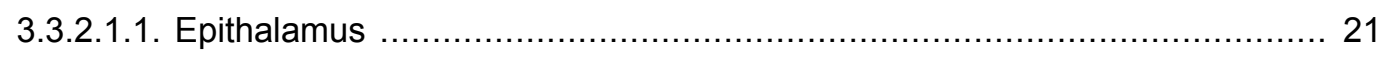

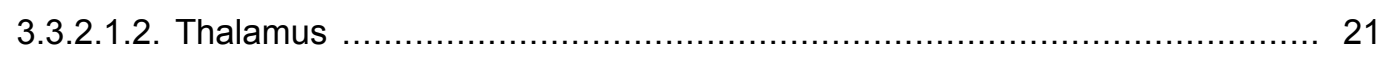

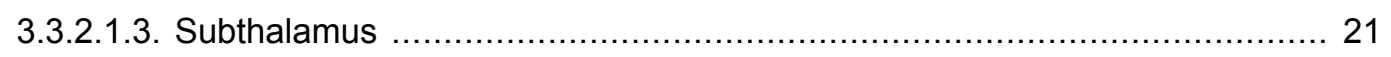

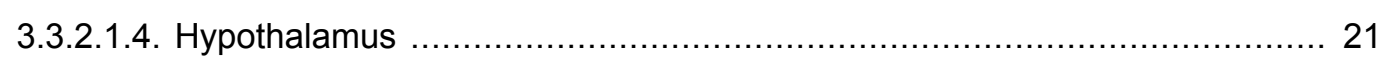

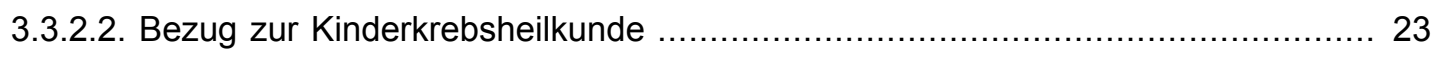

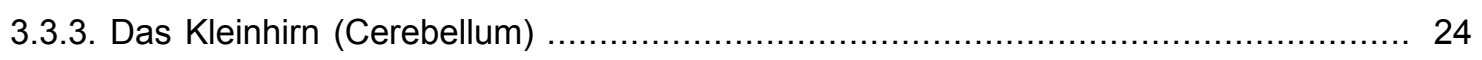

3.3.3.1. Aufbau des Kleinhirns ................................................................... 24

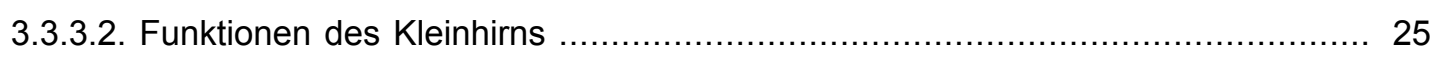

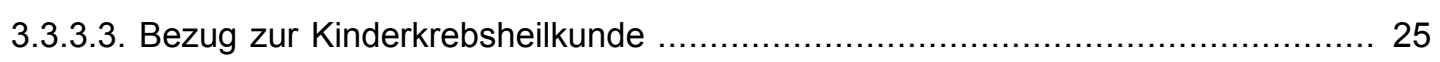

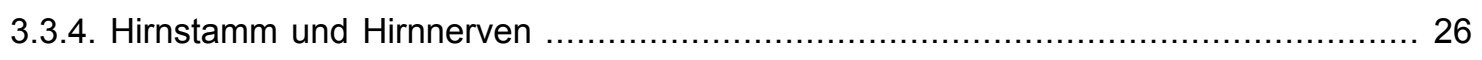

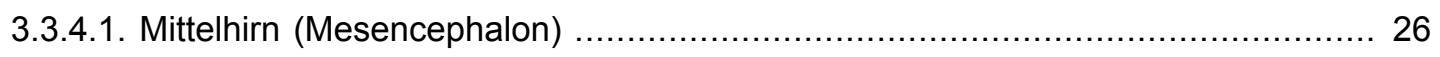

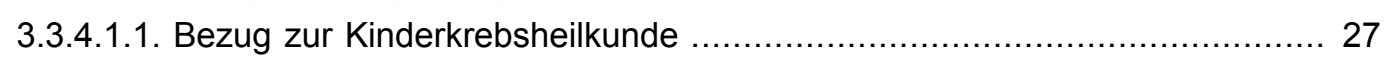

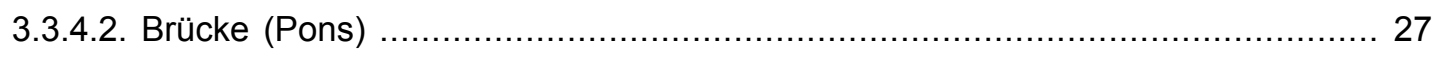




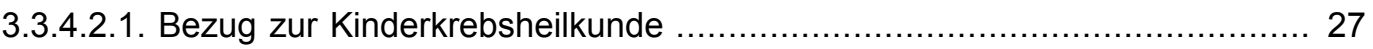

3.3.4.3. Verlängertes Mark (Medulla oblongata) ................................................ 27

3.3.4.3.1. Bezug zur Kinderkrebsheilkunde .................................................... 28

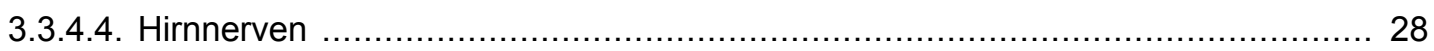

3.3.4.4.1. I. Hirnnerv: Der Riechnerv (Nervus olfactorius) .................................. 28

3.3.4.4.2. II. Hirnnerv: Der Sehnerv (Nervus opticus) .......................................... 29

3.3.4.4.3. III. Hirnnerv: Augenmuskelnerv (Nervus oculomotorius) ......................... 29

3.3.4.4.4. IV. Hirnnerv (Nervus trochlearis) ................................................ 30

3.3.4.4.5. V. Hirnnerv (Nervus trigeminus) ............................................... 30

3.3.4.4.6. VI. Hirnnerv: Augenmuskelnerv (Nervus abducens) ............................. 31

3.3.4.4.7. VII. Hirnnerv: Gesichtsnerv (Nervus facialis) .................................... 31

3.3.4.4.8. VIII. Hirnnerv: Gehör- und Gleichgewichtsnerv (Nervus vestibulocochlearis oder Nervus statoacusticus) …......................................... 32

3.3.4.4.9. IX. Hirnnerv: Zungen-Rachennerv (Nervus

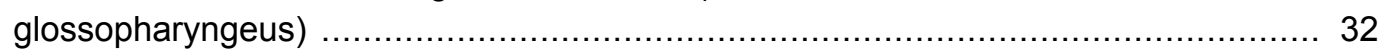

3.3.4.4.10. X. Hirnnerv (Nervus vagus) ........................................................ 33

3.3.4.4.11. XI. Hirnnerv (Nervus accessorius) ................................................. 33

3.3.4.4.12. XII. Hirnnerv: Zungennerv (Nervus hypoglossus) .............................. 33

3.3.4.5. Mögliche Ursachen für Störungen von Hirnstamm- und

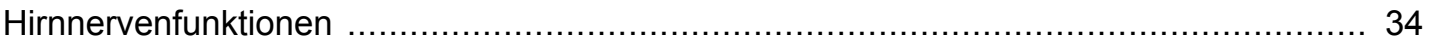

3.3.4.5.1. Erhöhter Druck im Schädelinneren ................................................ 34

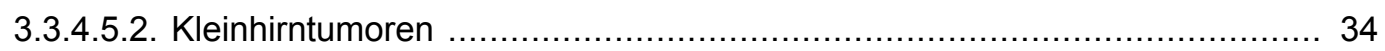

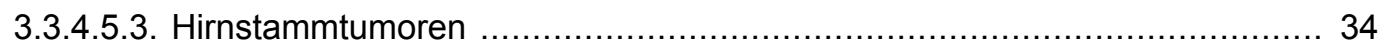

3.3.5. Lagebeschreibungen von Hirnstrukturen und von Tumoren im

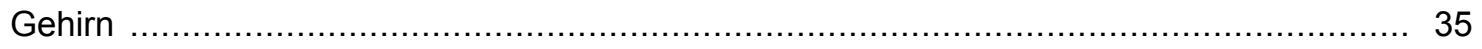

3.3.6. Das Rückenmark (Medulla spinalis) und seine Nerven ..................................... 35

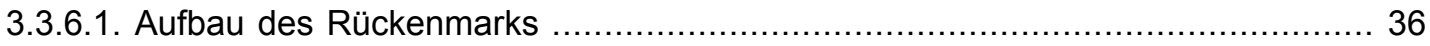

3.3.6.2. Funktion des Rückenmarks: Nachrichtenvermittlung zwischen

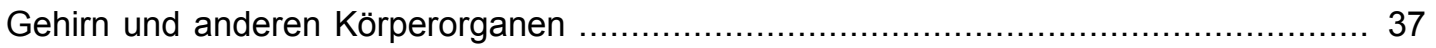

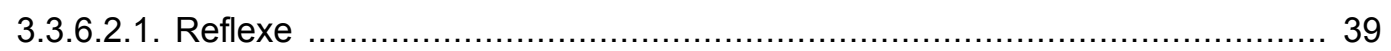

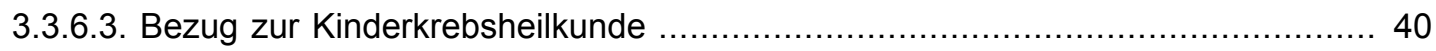

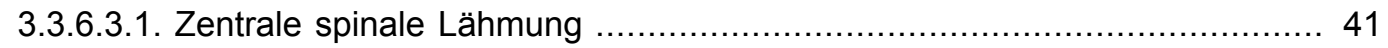

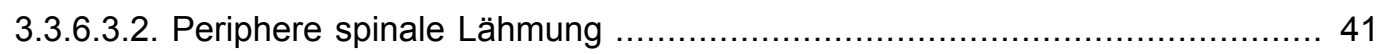

3.3.6.3.3. Halbseitenlähmung (inkompletter Querschnitt) .................................. 41

3.3.6.3.4. Komplette spinale Querschnittslähmung ........................................ 41

3.3.7. Lagebeschreibungen von Rückenmarksstrukturen und von Tumoren

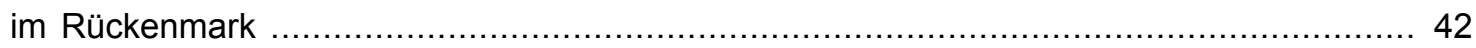

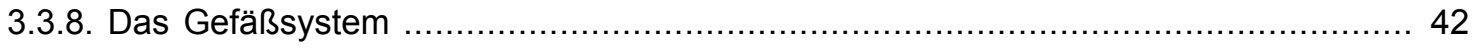

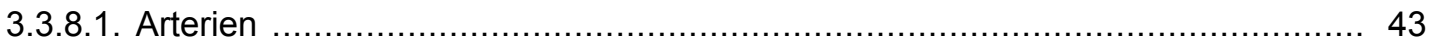

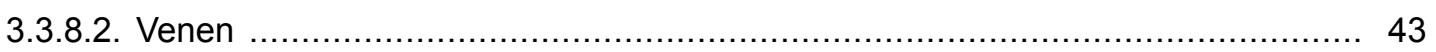

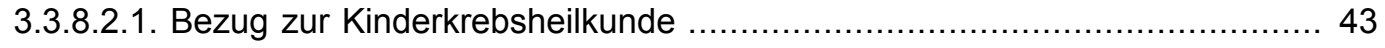

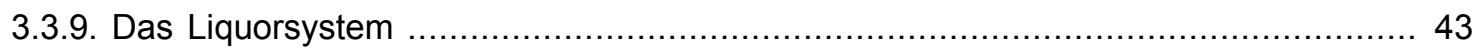

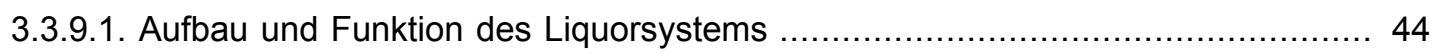

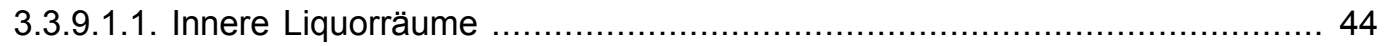




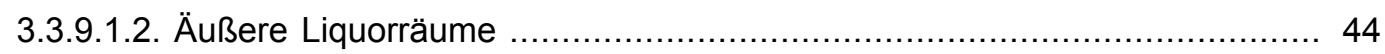

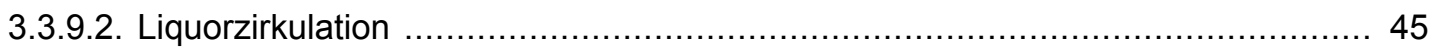

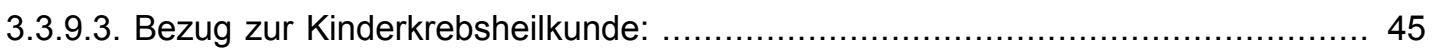

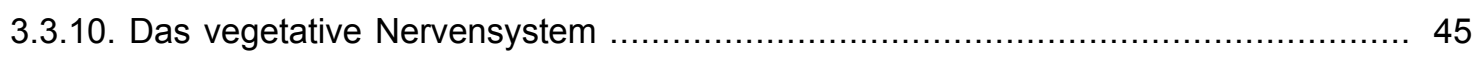

3.3.10.1. Aufbau und Funktion des vegetativen Nervensystems .............................. 46

3.3.10.2. Sympathisches Nervensystem (Sympathicus) ........................................ 46

3.3.10.3. Parasympathisches Nervensystem (Parasympathicus) ................................ 48

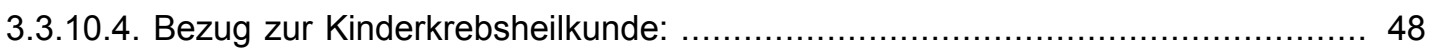

3.3.11. Funktionelle Systeme (Nachrichtensysteme) ..................................................... 48

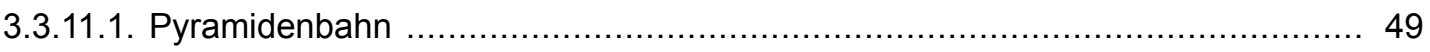

3.3.11.1.1. Bezug zur Kinderkrebsheilkunde ............................................... 49

3.3.11.2. Extrapyramidal-motorisches System ........................................................ 49

3.3.11.2.1. Bezug zur Kinderkrebsheilkunde ............................................. 49

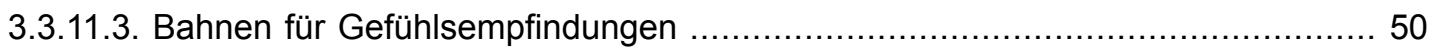

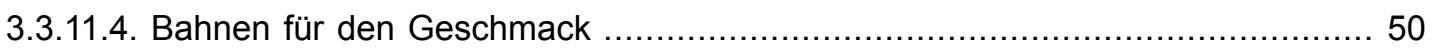

3.3.11.5. Bahnen für den Geruchssinn ............................................................... 50

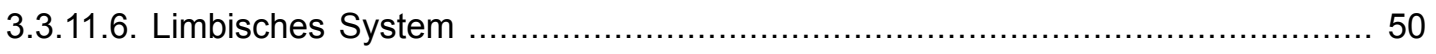

3.3.11.6.1. Bezug zur Kinderkrebsheilkunde .......................................... 51

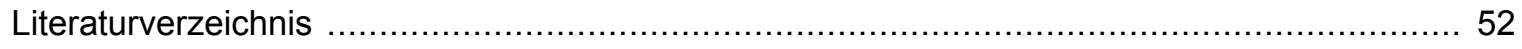

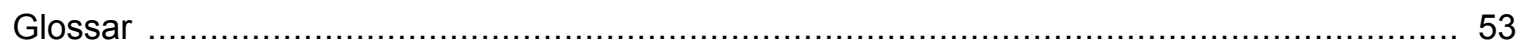




\section{Aufbau und Funktion des Zentralnervensystems (ZNS)}

Zur Orientierung innerhalb dieses sehr umfangreichen Gebiets haben wir diesen Text in folgende Abschnitte eingeteilt:

a. Das Nervensystem des Menschen - allgemeine Einführung und Gliederung

b. Das zentrale Nervensystem (Zentralnervensystem; ZNS)

c. Aufgaben des ZNS

d. Feingeweblicher Aufbau des ZNS

e. Einteilung des ZNS:

- Das Großhirn (Endhirn)

- Das Zwischenhirn

- Das Kleinhirn

- Hirnstamm und Hirnnerven

- Das Rückenmark und seine Nerven

- Das Gefäßsystem

- Das Liquorsystem

- Das vegetative (autonome) Nervensystem

- Funktionelle Systeme (Nachrichtensysteme)

Wichtig: Bitte beachten Sie, dass wir bei der hier vorgenommenen Einteilung und Beschreibung von Strukturen des Zentralnervensystems an verschiedenen Stellen auch die damit in Verbindung stehenden Anteile des peripheren Nervensystems berücksichtigen [siehe peripheres Nervensystem]. So werden beispielsweise Hirnnerven oder Spinalnerven, die zum peripheren Nervensystem gehören, aufgrund ihrer Ursprungsorte im ZNS im Kapitel zu „Hirnstamm“ beziehungsweise „Rückenmark“ mit beschrieben.

Wie gehen hier außerdem kurz auf das vegetative (autonome) Nervensystem ein (siehe gleichnamiges Kapitel), welches Anteile sowohl im Zentralnervensystem als auch im peripheren Nervensystem hat. Dasselbe gilt für das somatische Nervensystem, das zum Beispiel im Kapitel 
zu den Hirnnerven (aufsteigende Nervenbahnen der Sinnesorgane wie Riechbahn, Sehbahn, Hörbahn) oder im Kapitel "Funktionelle Systeme" (Pyramidenbahn) Erwähnung findet.

Informationen zur Einteilung des Nervensystems erhalten Sie im Kapitel "Einführung Nervensystem".

Anmerkung: Die Informationen erheben nicht den Anspruch auf Vollständigkeit, und Einzelheiten sollten Sie immer persönlich mit Ihrem Behandlungsteam erörtern. Die Informationen dienen als Grundlage für ein besseres Verständnis der Probleme, die ein Tumor im Nervensystem verursachen kann, und somit auch dazu, die Behandlungsstrategien für die betroffenen Patienten besser nachvollziehen zu können. Als Quelle für diesen Text diente vor allem die unten angegebene Literatur.

\section{Basisliteratur}

Kahle W (Hrsg.) Taschenatlas der Anatomie für Studium und Praxis: 3, Nervensystem und Sinnesorgane, Georg-Thieme-Verlag 6. überarbeitete Aufl. 1991, 3-13-552406-X isbn

Riede UN (Hrsg.) Allgemeine und spezielle Pathologie, Georg-Thieme-Verlag 5. komplett überarb. Aufl., 2004, 3-13-683305-8 isbn

Schmidt, RF Physiologie des Menschen, Springer Verlag 29., vollst. neu bearb. und aktualisierte Aufl., 2005, 3-540-21882-3 isbn

Stöhr M, Brandt T, Einhäupl KM (Hrsg.) Neurologische Syndrome in der Intensivmedizin. Differentialdiagnose und Akuttherapie, Kohlhammer Verlag 1190, 3-17-010223-0 isbn

Trepel M Neuroanatomie - Struktur und Funktion, Elsevier GmbH, Urban \& Fischer Verlag 3. Auflage 2004, 978-3-437-41297-4 isbn 


\section{Das Nervensystem des Menschen - allgemeine Einführung und Gliederung}

Bei den einfachsten Lebewesen wird die Nachrichtenübermittlung von Sinneszellen übernommen. Diese werden durch Umweltreize erregt und leiten dieses Signal über einen Fortsatz zu einer Muskelzelle weiter. So entsteht die einfachste Reaktion auf einen Umweltreiz.

Bei höheren, komplizierteren Lebensformen ist zwischen die Sinnes- und die Muskelzelle jeweils eine weitere Zelle geschaltet: die Nervenzelle. Diese übernimmt die Nachrichtenübermittlung auf zahlreiche Muskelzellen und/oder weitere Nervenzellen, wodurch ein Nervennetz entsteht.

Das Nervensystem des Menschen kann auf verschiedene Weise eingeteilt werden.

In erster Linie unterscheidet man ein:

- Zentrales Nervensystem (auch Zentralnervensystem; abgekürzt ZNS): Es besteht aus Gehirn und Rückenmark.

- Peripheres Nervensystem (PNS): Es besteht aus den zahlreichen Nerven, die den Körper (Kopf, Rumpf, Extremitäten) durchziehen und als sensible oder motorische Leitungsbahnen entweder Impulse von der Peripherie zum ZNS (sensibel) oder vom ZNS in die Peripherie (motorisch) tragen.

Sowohl im zentralen wie im peripheren Nervensystem unterscheidet man darüber hinaus:

- Somatisches Nervensystem: Es dient motorisch der willkürlichen Ansteuerung der Skelettmuskeln und sensibel der bewussten Wahrnehmung der Körperperipherie.

- Vegetatives (auch viszerales oder autonomes) Nervensystem: Es dient der unbewussten und unwillkürlichen Steuerung der inneren Organe und setzt sich aus zwei Anteilen, dem Sympathicus und dem Parasympathicus, zusammen.

Da bei Kindern und Jugendlichen Tumoren des Nervensystems hauptsächlich im zentralen Nervensystem (ZNS) vorkommen, haben wir den Hauptschwerpunkt dieses Textes auf das ZNS gelegt. 


\section{Funktion des Nervensystems}

Das Nervensystem übermittelt Nachrichten. Dabei ist es sowohl mit dem Organismus als auch der Umwelt eng verknüpft:

- Umweltreize werden von sensiblen Nerven (zum Beispiel Hautnerven der Hand) durch das Rückenmark zu bestimmten Regionen im Gehirn geleitet.

- Als Antwort sendet das Gehirn einen Befehl, beispielsweise über die motorischen Nerven, an die Muskeln.

- Von dort geben bestimmte Sinneszellen dem Gehirn aus dem Körperinneren die Rückmeldung, dass der Befehl ausgeführt wurde und ob es dabei Probleme gab oder nun alles in Ordnung ist.

Man kann sich also vorstellen, dass jedwede Störung dieser Nachrichtenwege, zum Beispiel durch einen Tumor, einen Informationsverlust bedeutet und dadurch schwerwiegende Folgen für den menschlichen Organismus und sein Zusammenspiel mit der Umwelt haben kann. 


\section{Das zentrale Nervensystem (Zentralnervensystem; ZNS)}

Das Zentralnervensystem (ZNS) besteht aus Gehirn (Encephalon) und Rückenmark (Medulla spinalis).

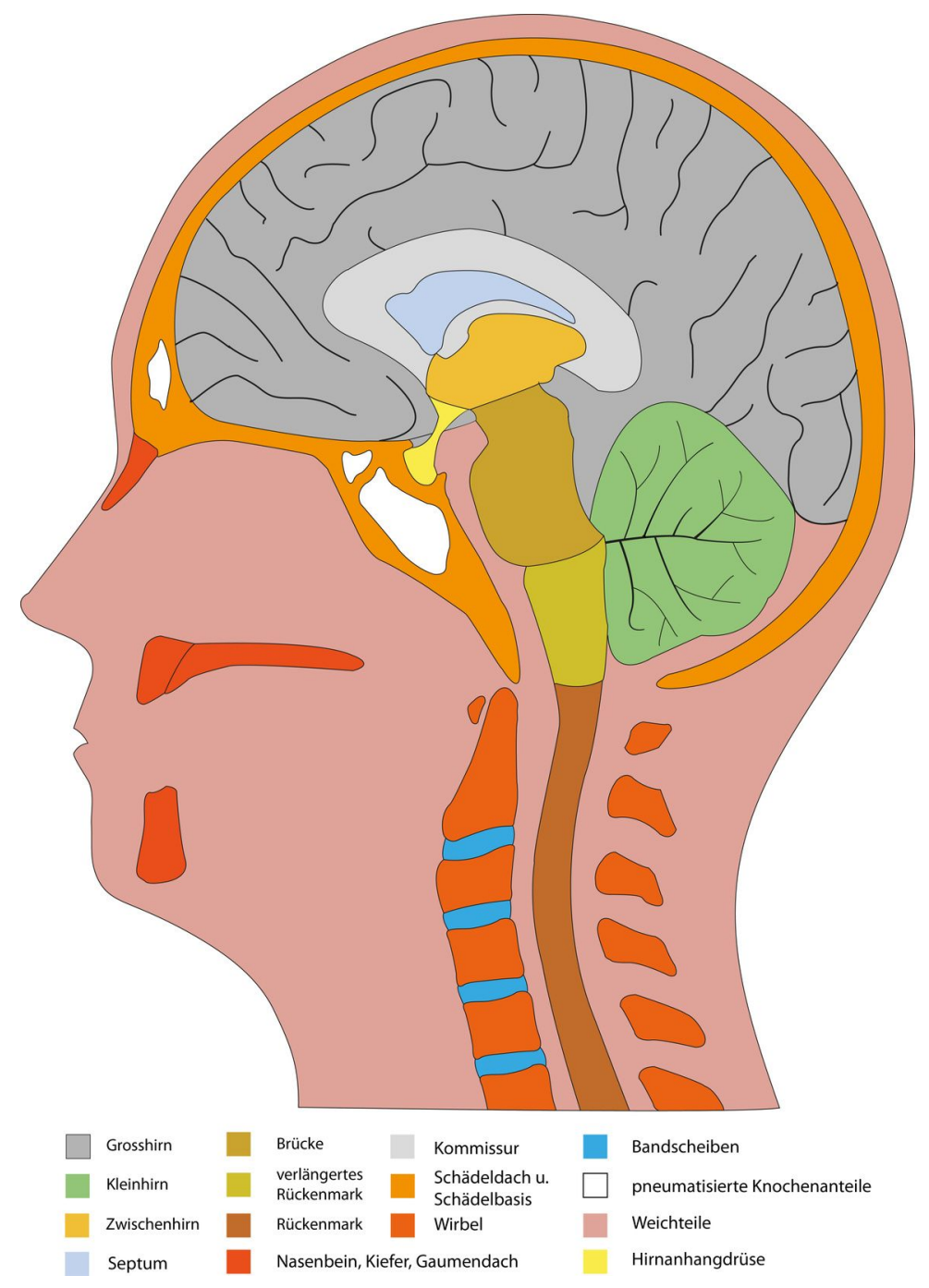

Gehirn und Rückenmark sind in die drei aus Bindegewebe bestehenden Hirn- beziehungsweise Rückenmarkshäute (Mengingen) eingehüllt:

- Harte Hirnhaut (Dura mater)

- Spinngewebshaut (Arachnoidea)

- Weiche Hirnhaut (Pia mater)

Während die Dura mater als äußerste Schicht an den umgebenden Schädel- bzw. Wirbelknochen angrenzt, legt sich die Pia mater als innerstes Blatt direkt an die Oberfläche von Gehirn 
bzw. Rückenmark an. Der Raum zwischen der Spinngewebshaut und der weichen Hirn-I Rückenmarkshaut ist mit Flüssigkeit gefüllt, dem Nervenwasser (auch Gehirn-RückenmarkFlüssigkeit, Liquor cerebrospinalis). Auf diese Weise ist das Zentralnervensystem allseitig durch knöcherne Wände und eine Flüssigkeit mit Polsterwirkung geschützt.

In der Spinngewebshaut verlaufen zahlreiche Blutgefäße. Die weiche Hirn-/Rückenmarkshaut versorgt Gehirn bzw. Rückenmark mit Nährstoffen aus dem Liquor.

Die Nerven des peripheren Nervensystems gelangen von ihren Ursprungsorten durch Löcher in der Schädelbasis (Hirnnerven) und durch Löcher zwischen den Bögen der Wirbelkörper (Spinalnerven) nach außen und ziehen zu Muskeln und Hautbezirken, um dorthin Nachrichten abzugeben beziehungsweise von dort Nachrichten zu empfangen.

\subsection{Aufgaben des Zentralnervensystems - Übersicht}

Die Aufgaben des Zentralnervensystems (ZNS) sind lebensnotwendig. Das ZNS ist verantwortlich für:

- die (über Nerven vermittelte) Kontrolle des Zusammenspiels von Körperhaltung und Bewegung,

- die Ermöglichung von Bewusstsein, Sprache, Denken (Verstand, Vernunft), Gedächtnis (Lernen und Erinnerung), Trieb, Gefühl und Schlaf-Wach-Rhythmus,

- die Vermittlung und Verarbeitung von Nachrichten aus der Umwelt und aus dem Körperinneren,

- die Regulation des gesunden Zusammenspiels aller lebensnotwendigen Systeme im menschlichen Körper (vegetatives, peripheres Nervensystem, innere Organe, Hormonhaushalt, Muskeln, Sinnesorgane, Blut und Blutkreislauf, Atmung).

Wie diese unterschiedlichen Aufgaben ausgeübt werden, wird in den folgenden Abschnitten dieses Textes erläutert.

\subsection{Feingeweblicher (histologischer) Aufbau des Zentralnervensystems}

Das Nervengewebe besteht aus Nervenzellen und Gliazellen. Darüber hinaus kommen überall im ZNS neuroektodermale Zellen vor, "Überbleibsel" aus der Embryonalentwicklung. Da sich aus all diesen Zelltypen ZNS-Tumoren entwickeln können, erhalten Sie im Anschluss einige Informationen über den Aufbau dieser Zellen und ihre Zusammenarbeit im Nervensystem. Blutgefäße und Hirnhäute gehören nicht zum Nervengewebe.

\subsubsection{Nervenzellen (Neuronen)}

Nervenzellen sind hauptsächlich für die Nachrichtenübertragung zuständig. 
Nervenzellen im reifen Zustand können sich nicht mehr teilen beziehungsweise vermehren. Das bedeutet, dass ab einem bestimmten Lebensalter kein Ersatz von alten, geschädigten oder zerstörten Zellen mehr möglich ist.

Aus diesem Grund ist es in der Kinderkrebsheilkunde so entscheidend, ob und in welchen Fällen beispielsweise mit einer Bestrahlung eines ZNS-Tumors begonnen wird. Ebenso sorgfältig muss die Entscheidung hinsichtlich der Strahlendosis gewählt werden, denn neben den Tumorzellen kann die Bestrahlung auch gesunde Nervenzellen schädigen.

\section{Eine Nervenzelle besteht aus:}

- Zellkörper (Perikaryon), der den Zellkern und damit das Erbgut der Zelle enthält,

- Fortsätzen, die Erregungen empfangen (Dendriten),

- Hauptfortsatz (Neurit oder Axon), der die Erregung zu einer Umschaltstelle (Synapse) weiterleitet; dort wird die Erregung entweder auf die nachgeschaltete (Nerven- oder Muskel-) Zelle weitergeleitet oder die Erregungsleitung wird gehemmt.

Mit ihren Fortsätzen und den Synapsen bilden die Nervenzellen ein Netzwerk, durch das wichtige Signale weitergegeben und unwichtige Signale unterdrückt werden.

Sowohl die Überleitung als auch die Hemmung von Erregungsausbreitungen an den Synapsen erfolgen beim Menschen jeweils durch chemische Substanzen (Neurotransmitter). Zu diesen gehören unter anderem Acetylcholin und die Katecholamine (Dopamin; Noradrenalin).

So übertragen zum Beispiel die Nervenzellen, die zum Sympathicus des vegetativen Nervensystems gehören, ihre Impulse innerhalb des Rückenmarks mittels Acetylcholin (cholinerge Nervenzellen), im Bereich der peripheren Nerven hingegen mittels Noradrenalin (adrenerge Nervenzellen).

Aufbau, Abbau und Speicherung der Neurotransmitter können durch Medikamente und auch durch bestimmte Tumoren beeinflusst werden, so dass entweder ein Überschuss oder ein Mangel von Transmittern erzeugt wird. Dies wiederum kann zu Veränderungen von Körperfunktionen (wie Muskelbewegungen, Gefühlen, Kreislauf) führen.

\subsubsection{Gliazellen}

Die Gliazellen bilden in erster Linie das Stütz-, Hüll- und ernährende Gewebe des Nervensystems. Man unterscheidet folgende Gliazell-Formen:

- die Makroglia (Astroglia)

- die Oligodendroglia

- die Mikroglia

- Ependym 


\subsubsection{Makroglia (Astroglia)}

Die Makroglia besteht aus Astrozyten. Diese Zellen haben einen großen Zellkern und viele sternförmig vom Zellkern abgehende Fortsätze. Sie sind am Stoffaustausch zwischen Nerven- und Blutgefäßzellen und damit maßgeblich an der Ernährung des Nervengewebes beteiligt.

Astrozyten wirken außerdem bei der Erregungsübertragung im Bereich der Synapsen von Nervenzellen mit (siehe Abschnitt "Nervenzellen"), indem sie die Weiterleitungsgeschwindigkeit von Erregungen beeinflussen und die Aufnahme von Neurotransmittem steuern. Bei krankhaften Prozessen haben sie außerdem Reparaturfunktionen und sind an der Narbenbildung (Gliose) beteiligt.

Die Makroglia grenzt das Hirngewebe an seiner Oberfläche gegen die Hirnhäute und die Blutgefäße ab - ein Phänomen, das die Blut-Hirn-Schranke möglich macht. Unter der Blut-Hirn-Schranke versteht man die natürliche Abgrenzung des Zentralnervensystems vom Blutkreislauf. Sie hat die Aufgabe, gewisse Stoffe (zum Beispiel Krankheitserreger, Gifte) nicht aus dem Blut in das Gehirngewebe eindringen zu lassen.

Bezug zur Kinderkrebskunde: Aus entarteten Astrozyten können Astrozytome beziehungsweise astrozytäre Gliome entstehen. Ein häufiger ZNS-Tumor im Kindes- und Jugendalter, der aus entarteten Astrozyten entsteht, ist das pilozytische Astrozytom, das zu den niedrigmalignen Gliomen gehört.

\subsubsection{Oligodendroglia}

Oligodendrozyten besitzen kleinere Zellkerne als Astrozyten und vergleichsweise wenige Fortsätze, die kaum verzweigt sind. Sie umhüllen als "Markscheiden" die Fortsätze der Nervenzellen (siehe Abschnitt "Nervenzellen").

Bezug zur Kinderkrebsheilkunde: Ein aus veränderten Oligodendrozyten entstandener Tumor, der bei Kindern und Jugendlichen vorkommt, ist zum Beispiel das Oligodendrogliom.

\subsubsection{Mikroglia}

Mikroglia besteht aus kleinen Zellen mit ovalen Zellkernen und kurzen, stark verzweigten Fortsätzen. Mikrogliazellen können sich fortbewegen. Sie dienen dem Abräumen (Phagozytose) von Fremdkörpern und abgestorbenen Zellbestandteilen nach einer Gewebeschädigung und bilden daher einen Teil des zellulären Immunsystems.

\subsubsection{Ependym}

Ependymzellen sind Gliazellen, die die Innenwände der Hirnkammern (Hirnventrikel) und des Rückenmarkkanals auskleiden. Sie sind für Liquorproduktion, -transport und -abbau verantwortlich.

Bezug zur Kinderkrebsheilkunde: Aus entarteten Ependymzellen entstehen Ependymome, eine Gruppe von ZNS-Tumoren des Kindes- und Jugendalters.

\subsubsection{Neuroektodermale Zellen}


Neuroektodermale Zellen sind kleine, runde Zellen, die sich häufig teilen und in der Regel sehr einfach (primitiv) aufgebaut, unreif und somit undifferenziert sind. Sie gelten als Überbleibsel aus der Embryonalentwicklung des Zentralnervensystems.

Bezug zur Kinderkrebsheilkunde: Aus neuroektodermalen Zellen kann, wenn sie entarten und sich ungehemmt vermehren, ein primitiver, neuroektodermaler Tumor (PNET) entstehen. Dazu gehört zum Beispiel das Medulloblastom, der häufigste bösartige ZNS-Tumor im Kindes- und Jugendalter.

\subsection{Einteilung des Zentralnervensystems}

Das Zentralnervensystem (ZNS) wird in die fünf folgenden Hauptabschnitte eingeteilt:

a. Großhirn

b. Zwischenhirn (Thalamus, Hypothalamus, Epithalamus)

c. Kleinhirn

d. Hirnstamm(Mittelhirn, Brücke, verlängertes Mark)

e. Rückenmark

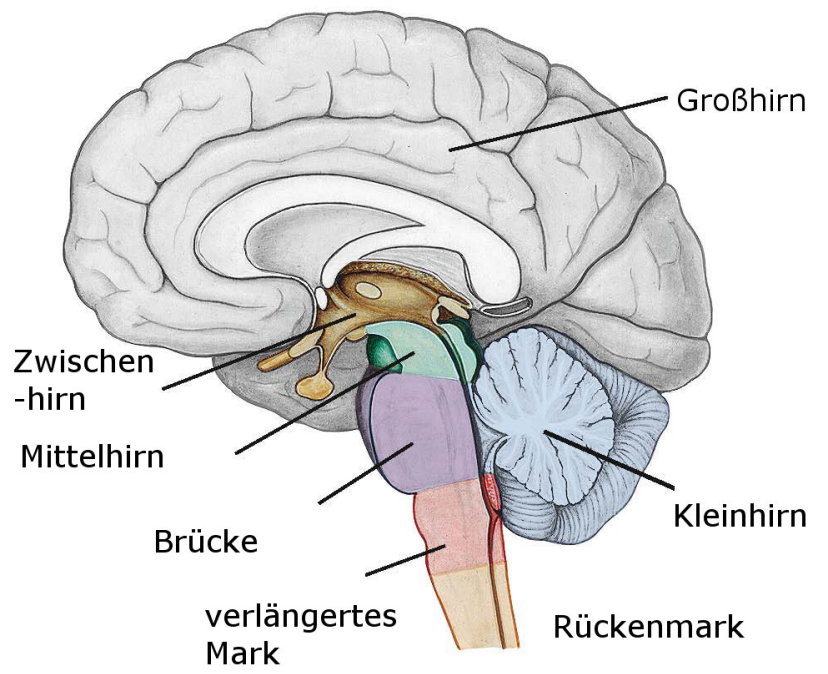

Die Einzelheiten zu diesen Komponenten des ZNS werden jeweils in eigenen Abschnitten dieses Textes erläutert.

Weiße und graue Substanz

Zerlegt man das Gehirn in Scheiben, so, wie es beispielsweise theoretisch während einer Magnetresonanztomographie erfolgt, so erkennt man auf den Schnittflächen die weiße und die graue Substanz (substantia alba und substantia grisea). 
Die graue Substanz wird durch eine Ansammlung von Nervenzellkörpern, die weiße durch Nervenfaserbahnen, genauer gesagt, durch Fortsätze der Nervenzellen, gebildet. Letztere erscheinen durch ihre weißliche Umhüllung, die Markscheiden, hell (siehe hierzu Abschnitt zum feingeweblichen Aufbau der Nervenzellen).

Im Großhirn liegt die graue Substanz außen (Großhirnrinde; Cortex), die weiße innen (siehe Abbildung im Teaser links). Im Rückenmark ist die Verteilung umgekehrt, im Zwischenhirn und im Hirnstamm sind graue und weiße Substanz wechselnd verteilt.

\subsubsection{Das Großhirn (Endhirn; Cerebrum)}

Dieser Abschnitt beschreibt den Aufbau des Großhirns und wie es mit allen anderen Funktionseinheiten des Zentralnervensystems (ZNS) zusammenarbeitet. Viele ZNS-Tumoren im Kindes- und Jugendalter wachsen im Großhirn, zum Beispiel supratentorielle PNET, Ependymome oder niedrigmaligne Gliome im Bereich der Sehbahn.

$\mathrm{Zu}$ wissen, welche Strukturen dort möglicherweise durch einen Tumor geschädigt werden, erleichtert beispielsweise, das Vorgehen des Neurochirurgen, die Möglichkeiten einer Strahlentherapie und auch die Krankheitszeichen besser zu verstehen.

\subsubsection{Aufbau des Großhirns}

Das Großhirn gliedert sich in zwei Hälften, die Hemisphären, die durch den Balken (Corpus callosum) miteinander verbunden sind. Jede Hemisphäre wird in vier Hirnlappen (Lobi cerebri) gegliedert:

- Frontallappen (Lobus frontalis)

- Scheitellappen (Lobus parietalis)

- Schläfenlappen (Lobus temporalis)

- Hinterhauptslappen (Lobus occipitalis) 


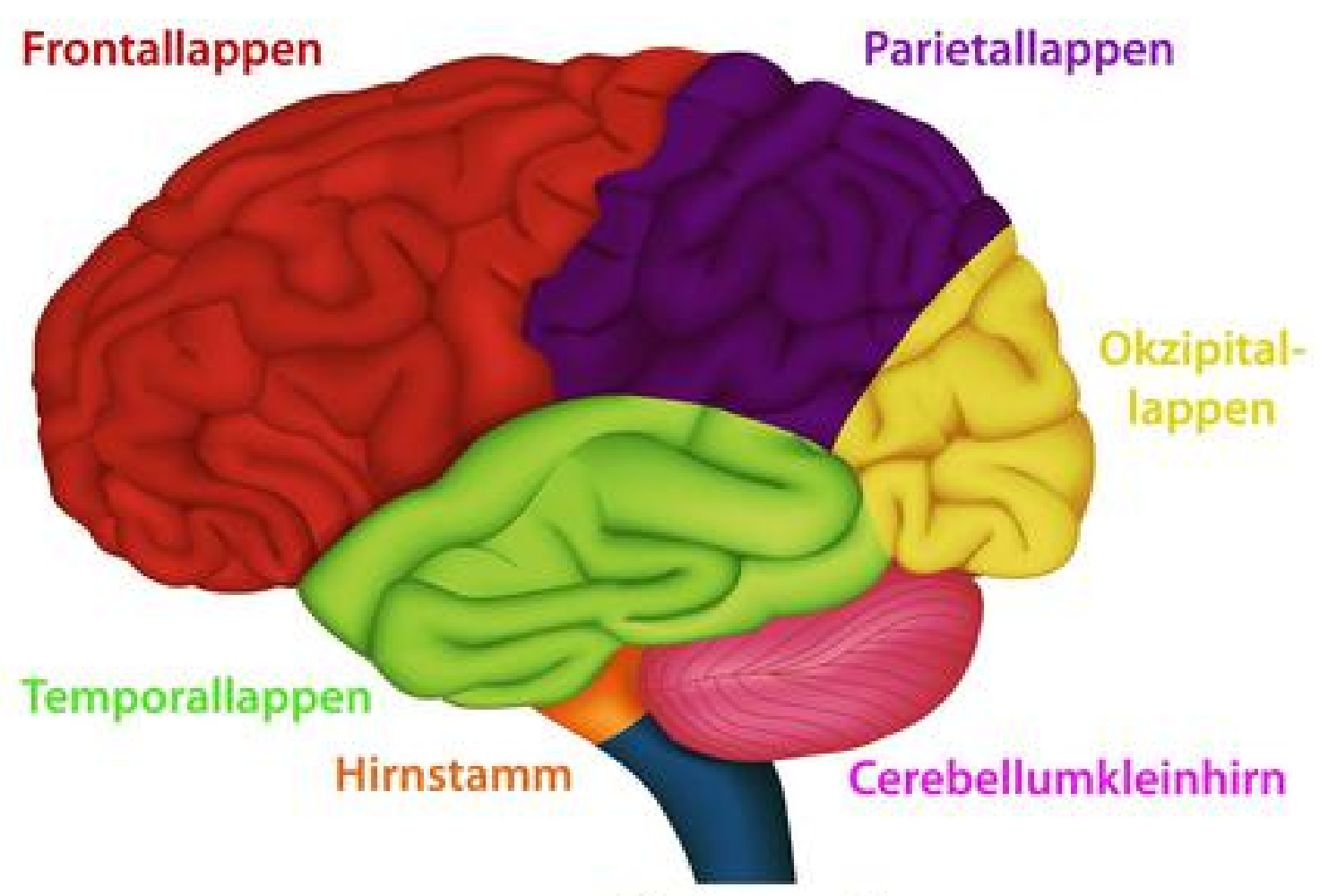

\section{Rückenmark}

Die Oberfläche der Hemisphären besteht aus Furchen (Sulci) und Windungen (Gyri), die der Oberflächenvergrößerung dienen. Manche Furchen sind in allen Gehirnen gleich ausgebildet, während andere individuell verschieden sind und dadurch jedem Gehirn sein eigenes Oberflächenrelief verleihen.

Beinahe alle Furchen und Windungen sind mittlerweile benannt. Wir wollen hier auf die Aufzählung der einzelnen Bezeichnungen verzichten, einige von ihnen allerdings im Zusammenhang mit ihrer Funktion im Verlauf dieses Abschnitts erwähnen. 


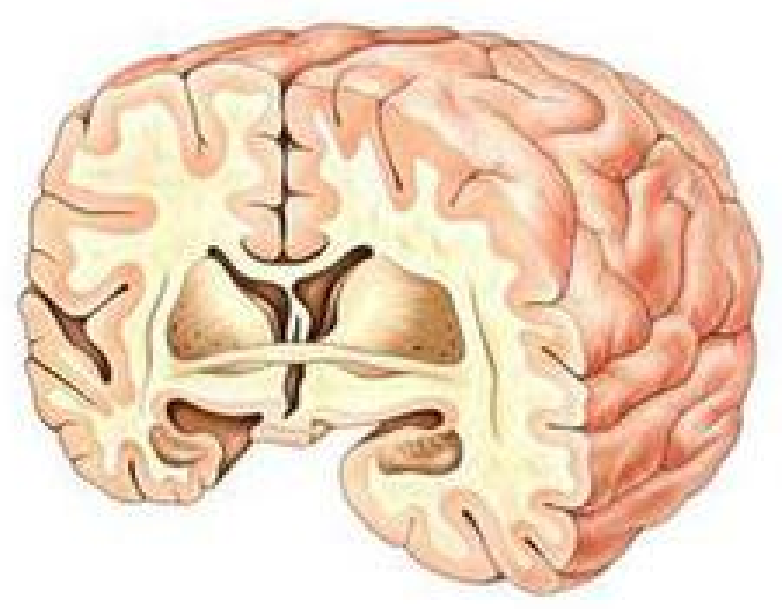

\subsubsection{Die Großhirnrinde}

Die Großhirnrinde (Cortex cerebri) wird nach verschiedenen Gesichtspunkten unterteilt:

- Entsprechend ihrer entwicklungsgeschichtlichen Entstehung erfolgt eine Einteilung in unterschiedlich alte Gebiete (zum Beispiel Paleo-, Archi- und Neocortex).

- Aufgrund ihrer feingeweblichen Eigenschaften werden verschiedene Rindenbereiche unterschieden, beispielsweise die Hippocampusformation (siehe Abschnitt "Funktionen des Großhirns").

- Darüber hinaus wird die gesamte Großhirnrinde in 52 Rindenfelder (Brodmann-Areale oder Areae) eingeteilt, die die Endstätten der aufsteigenden Nachrichten-/Nervenbahnen aus Rückenmark, Hirnstamm, Zwischenhirn und Kleinhirn darstellen. Einige dieser Rindenfelder (Areale) sind in der folgenden Abbildung erkennbar (wie das Hörzentrum und das Sehzentrum). 


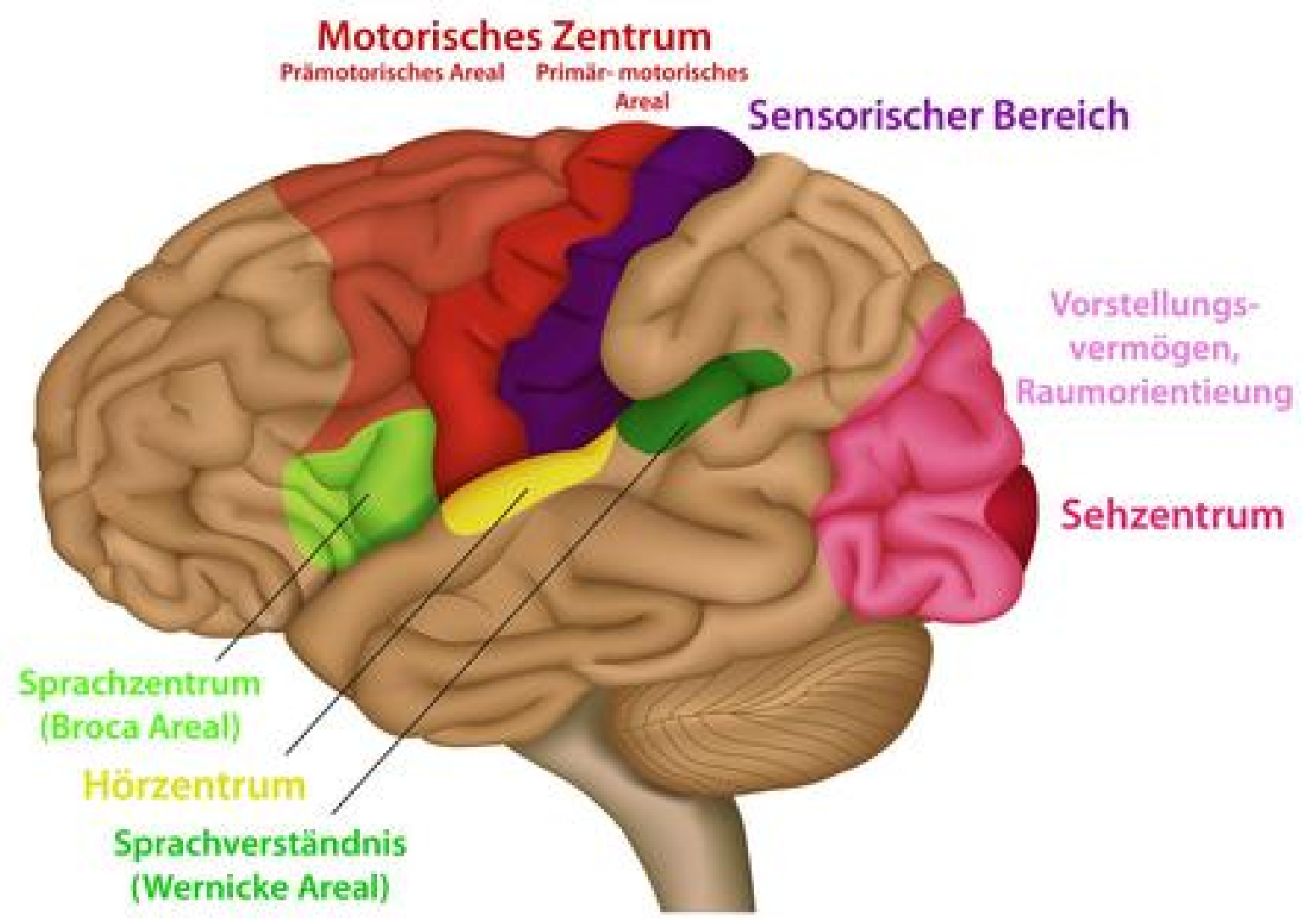

\subsection{Das Marklager}

Beim Marklager handelt es sich um Nervenfasermassen, die entweder von Nervenzellen der Großhirnrinde abgehen oder zu ihr hinziehen. Man unterscheidet dabei drei verschiedene Fasersysteme:

- Die Projektionsfasern stellen auf- und absteigende Verbindungen zwischen der Hirnrinde und allen unter ihr gelegenen (subkortialen) Zentren her. Die von der Rinde absteigende Bahnen laufen fächerförmig zusammen und bilden tief im Inneren des Großhirns eine Region, die innere Kapsel (Capsula interna) genannt wird. Diese wiederum enthält die verschiedenen Bahnen zum Thalamus, zur Brücke (im Hirnstamm) und zum Rückenmark. Weitere wichtige Projektionsbahnen sind die Hör- und die Sehbahn.

- Die Assoziationsfasern verbinden verschiedene Rindenbezirke untereinander.

- Die Kommissurenfasern verknüpfen die Rindenbereiche der beiden Großhirnhälften miteinander. Sie ziehen durch den Balken (Corpus callosum).

\subsection{Nervenzellkerne (Basalganglien/Stammganglien) im Marklager}

Die Basalganglien oder Stammganglien sind Gruppen von Nervenzellkernen (also graue Substanz), die in der Tiefe der weißen Substanz beider Hemisphären liegen. Man unterscheidet verschiedene Basalganglien (bezeichnet zum Beispiel als Claustrum, Globus pallidum oder Corpus 
striatum). Alle diese Kerne haben in ihrem Zusammenspiel eine wichtige Funktion bei der Regulation der Motorik, sie sind also für bestimmte Muskelaktivitäten zuständig (siehe Abschnitt "Funktionelle Systeme", extrapyramidal-motorisches System).

\subsubsection{Funktionen des Großhirns}

An die Großhirnrinde ist unter anderem das Bewusstsein geknüpft. Nur diejenigen Sinnesreize werden bewusst, welche bis zur Großhirnrinde weitergeleitet werden. Hier kommen über die Nervenfaserbahnen des Marklagers alle Sinnesreize an und werden als Informationen in den zugehörigen Rindengebieten ausgewertet.

Von dort aus ziehen dann die entsprechenden Reizantworten über das Marklager und verschiedene Umschaltstellen in Zwischenhirn, Hirnstamm und Rückenmark in die Körperumgebung.

Die verschiedenen Zuständigkeitsbereiche im Großhirn sollen im Folgenden, zum Teil unter Zuhilfenahme der Lappen-Einteilung, näher beschrieben werden.

Anmerkung: Nur der Mensch besitzt die Fähigkeit der Sprache. Als innere Sprache ist sie eine Voraussetzung für das Denken; gesprochen ermöglicht sie die Kommunikation und geschrieben die Weitergabe von Informationen über Jahrtausende hinweg. Die Fähigkeit zur Sprache ist unmittelbar gebunden an die Unversehrtheit bestimmter Rindengebiete des Großhirns, die in der Regel nur in einer Gehirnhälfte (Hemisphäre) liegen. Diese wird als dominante Hemisphäre bezeichnet und ist beim Rechtshänder meist die linke, beim Linkshänder meist die rechte. Die Sprachfähigkeit kann allerdings auch in beiden Hemisphären vertreten sein.

\subsection{Frontallappen}

Im Frontallappen liegt unter anderem die Präzentralregion. Hier befinden sich die beiden Rindenfelder, die die motorische Rinde (Areas 4 und 6) bilden (siehe Abbildung zu den Rindenfeldern der Großhirnrinde oben). Die motorische Rinde ist das Hauptursprungsgebiet der Nachrichtenvermittlung für Muskelaktivitäten. Dabei ist jede Körperhälfte in der gegenseitigen Hemisphäre vertreten.

Ein weiteres Rindenfeld (Area 8) gilt als das Blickzentrum für willkürliche Augenbewegungen. Zwei Rindenfelder (Area 44 und 45) der dominanten Hemisphäre bilden das motorische Sprachzentrum, auch Broca'sches Feld genannt (siehe Abbildung oben).

\section{Bezug zur Kinderkrebsheilkunde}

Krankheitszeichen von Patienten mit einem Hirntumor im Frontalhirn (frontaler Hirntumor) können zum Beispiel wie folgt entstehen und aussehen:

Bei Schädigungen der linken motorischen Rinde kommt es zu Lähmungen und Veränderungen der Muskelspannung von Gesichts-, Arm- und/oder Beinmuskulatur der rechten Körperhälfte.

Kommt es zu einer Schädigung im motorischen Sprachzentrum, ist der Patient nicht mehr in der Lage, Worte zu formulieren oder auszusprechen, während das Sprachverständnis erhalten bleibt (motorische Aphasie).

Schädigungen im Bereich der ganz vorn und an der Unterseite liegenden Rindengebiete des Frontallappenshabenmanchmal schwere Persönlichkeitsveränderungen zur Folge. Dabei 
sind dann besonders Eigenschaften wie "Initiative ergreifen", "Zielstrebigkeit", "Konzentration", "Kritikfähigkeit", sowie "Anstands-", "Takt-" und "Schamgefühl" gestört.

\subsection{Scheitellappen (Parietallappen)}

Im Scheitellappen (Parietallappen) liegt unter anderem die Postzentralregion. Die Felder 1, 2 und 3 der vordersten Windung des Scheitellappens (Gyrus postcentralis) bilden die Endstätte aller Bahnen für die Gefühlsempfindungen aus Körperinnerem und Umwelt (sensible Bahnen) und damit die somatosensorische Rinde (siehe sensorischer Bereich in Abbildung oben).

\section{Bezug zur Kinderkrebsheilkunde}

Ein Hirntumor im Scheitellappen (parietaler Hirntumor) kann zum Beispiel folgende Folgen für die verschiedenen Sinneseindrücke haben:

- Störungen der Oberflächen- und Tiefensensibilität (also Wahrnehmungsstörungen für Berührung und für die Stellung des Körpers im Raum)

- verschiedene Formen der Agnosie. Von einer Agnosie spricht man, wenn Sinneseindrücke zwar wahrgenommen werden, ihre Bedeutung aber nicht erkannt wird.

- Wenn der Tumor in der dominanten Hemisphäre liegt, kann es auch zu einem Verlust von Zahlenund Buchstabenverständnis und infolgedessen zu Störungen des Denkens mit Schreib-, Leseund/oder Rechenunfähigkeit kommen.

- Weiterhin werden Störungen des Körperschemas beobachtet, die sich beispielsweise als Unvermögen äußern können, rechts und links voneinander zu unterscheiden.

\subsection{Schläfenlappen (Temporallappen)}

In den Schläfenlappen liegt unter anderem die Hör- und die Sprachregion. Die Rindenfelder 41 und 42 bilden die Hörrinde, die die Endstätte aller Bahnen für das Hören ist (siehe Hörzentrum in Abbildung oben).

Im hinteren Bereich der oberen Schläfenlappenwindung (Gyrus temporalis superior) der dominanten Hemisphäre liegt das sensorische oder Wernicke Sprachzentrum (siehe Abbildung oben), bei dessen Schädigung eine Störung des Wortverständnisses eintritt (sensorische Aphasie). Die betroffenen Patienten geben dann eine Art "Wortsalat" von sich, und das von ihren Mitmenschen Gesagte klingt für sie wie eine unverständliche fremde Sprache.

Man nimmt außerdem an, dass die Schläfenlappenrinde eine wichtige Rolle der bewussten und unbewussten Verfügbarkeit der eigenen Vergangenheit und der in ihr gemachten Erfahrungen spielt, ohne die man sich in seiner Umwelt nicht zurechtfinden würde. Im Schläfenlappen liegt auch der Hippocampus, eine Sehpferdchen-förmige Struktur, die hauptsächlich für die Gedächtnisbildung zuständig ist. Sie ist Teil des limbischen Systems (siehe auch "Funktionelle Systeme").

\section{Bezug zur Kinderkrebsheilkunde}

Bei einem Hirntumor im Schläfenlappen (temporaler Hirntumor) können unter anderem Hör- und/ oder Sprachstörungen auftreten. Ist der Hippocampus mitbetroffen, sind oft Gedächtnisstörungen 
die Folge. Weiterhin können Schläfenlappenreizungen zu bestimmten Formen der Epilepsie, zu Halluzinationen und Fehleinschätzungen der gegenwärtigen Situation führen.

\subsubsection{Hinterhauptslappen (Okzipitallappen)}

Im Hinterhauptslappen liegt die Sehregion (siehe Sehzentrum in Abbildung oben). Area 17 bildet die Endigungsstätte aller Sehbahnen, die Sehrinde. Sie ist, zusammen mit anderen Rindenfeldern des Hinterhauptslappens, dafür zuständig, dass die Impulse, die die Netzhaut empfängt, bewusst gemacht und verarbeitet werden.

\section{Bezug zur Kinderkrebsheilkunde}

Schädigungen im Bereich des Hinterhauptslappens (zum Beispiel durch einen okzipitalen Hirntumor) können zu einer Rindenblindheit führen. Dabei werden Gegenstände mit den Augen gesehen, können aber nicht gedeutet oder erkannt werden.

\subsection{Stammganglien (Basalganglien) im Marklager}

Hier liegen die Nervenzellkerne für bestimmte automatisch ablaufende Muskelbewegungen, das heißt des extrapyramidal-motorischen Systems (siehe auch "Funktionelle Systeme").

Bei Schädigungen im Bereich des Marklagers kann es also neben dem Ausfall verschiedener Faserbahnen, die die einzelnen Rindengebiete mit Informationen versorgen und von diesen Informationen erhalten, zur Zerstörung von Stammganglien kommen. Folgen können sein:

- einerseits eine Störung der Muskelspannung, die sich in unwillkürlich auftretenden Muskelanspannungen in Form unkontrollierbarer Muskelzuckungen äußert (Dystonie),

- andererseits gesteigerte Muskelbewegungen, beispielsweise plötzliche, unvorhersehbare Bewegungen von Armen oder Beinen (Hyperkinese).

\section{Bezug zur Kinderkrebsheilkunde}

Manche große Tumoren können zu einer Schwellung des umgebenden Gewebes führen (perifokales Ödem). So kann beispielsweise ein großer Tumor im Großhirn ein Ödem im Marklager verursachen, das - obwohl der Tumor dieses nicht direkt schädigt - einen gewissen Druck auf die sich darin befindlichen Nervenzellkerngruppen ausübt. Auch dadurch können die oben genannten Krankheitszeichen entstehen.

Das Ausmaß dieser perifokalen Ödeme kann mittels einer Magnetresonanztomographie deutlich zu sehen sein, so dass nach bildgebender Diagnostik und je nach Zustand des Patienten zeitweilig eine abschwellende (antiödematöse) Behandlung erfolgen kann, zum Beispiel mit Steroidhormonen.

Die durch den Tumor und/oder die Schwellung verursachten Gewebeschädigungen und daraus folgenden (individuell unterschiedlich schweren) Krankheitszeichen beeinflussen die Therapie, zunächst vor allem die Möglichkeiten und das Ausmaß einer neurochirurgischen Tumorentfernung. 
Die Indikation für eine Operation wird zum Beispiel bei einem Tumor im Bereich des Sprachzentrums anders gestellt als bei einer Raumforderung in einer Hirnregion, die ein weniger hohes Risiko der neurologischen Folgeschädigung birgt.

\subsubsection{Das Zwischenhirn (Diencephalon)}

In Gesprächen mit dem Behandlungsteam werden immer wieder Begriffe auftauchen wie "thalamisch" oder "Hypothalamus" und "Hypophyse", oder auch "Hormonstatus", insbesondere dann, wenn es sich zum Beispiel um die Behandlung eines niedrigmalignen Glioms im Bereich der Sehbahn handelt. Aber auch im Rahmen der Strahlentherapie vieler Hirntumoren fallen diese Fachbegriffe, die sich allesamt auf Aufgabenbereiche des Zwischenhirns beziehen. Sie sollen deshalb im Folgenden näher erklärt werden.

\subsubsection{Aufbau und Funktion des Zwischenhirns}

Das Zwischenhirn ist die Fortsetzung des Hirnstamms in Richtung des Großhirns. Es lässt sich (von oben nach unten) in vier übereinander gelagerte Ebenen gliedern: den Epithalamus, den Thalamus, den Subthalamus und den Hypothalamus.

\subsection{Epithalamus}

Der Epithalamus ist eine Schaltstelle für Bahnen zwischen den Riechzentren sowie aus dem Hirnstamm und aus der Zirbeldrüse (Epiphyse oder Pinealisdrüse). Die Funktion der Zirbeldrüse besteht wahrscheinlich in der Bildung von Melatonin, einem Hormon, das auf die Veränderung von Lichtverhältnissen reagiert und dadurch zur Steuerung des Tag-Nacht-Rhythmus beiträgt.

\subsection{Thalamus}

Der Thalamus ist die Endigungsstätte der Bahnen für verschiedene Gefühlsempfindungen. $\mathrm{Er}$ ist durch auf- und absteigende Nervenfaserbahnen mit dem Hirnstamm, dem Kleinhirn und der Zirbeldrüse verbunden.

\subsection{Subthalamus}

Der Subthalamus liegt dem Mittelhirn an. Er enthält die Nervenzellkerne für bestimmte Muskelaktivitäten.

\subsection{Hypothalamus}

Der Hypothalamus bildet die unterste Etage des Zwischenhirns. Aus inm stülpt sich ein Teil der Hirnanhangsdrüse (Hypophyse) heraus. Er ist das oberste Regulationszentrum für das vegetative Nervensystem (siehe auch Kapitel "Vegetatives Nervensystem").

Der Hypothalamus beeinflusst verschiedene Organe, indem er bestimmte Hormone produziert, die wiederum die Bildung und Ausschüttung anderer Hormone in der Hypophyse regulieren. Die Hypophysenhormone stimulieren ihrerseits die Produktion und Ausschüttung von Hormonen aus den verschiedenen Hormondrüsen des Körpers. 


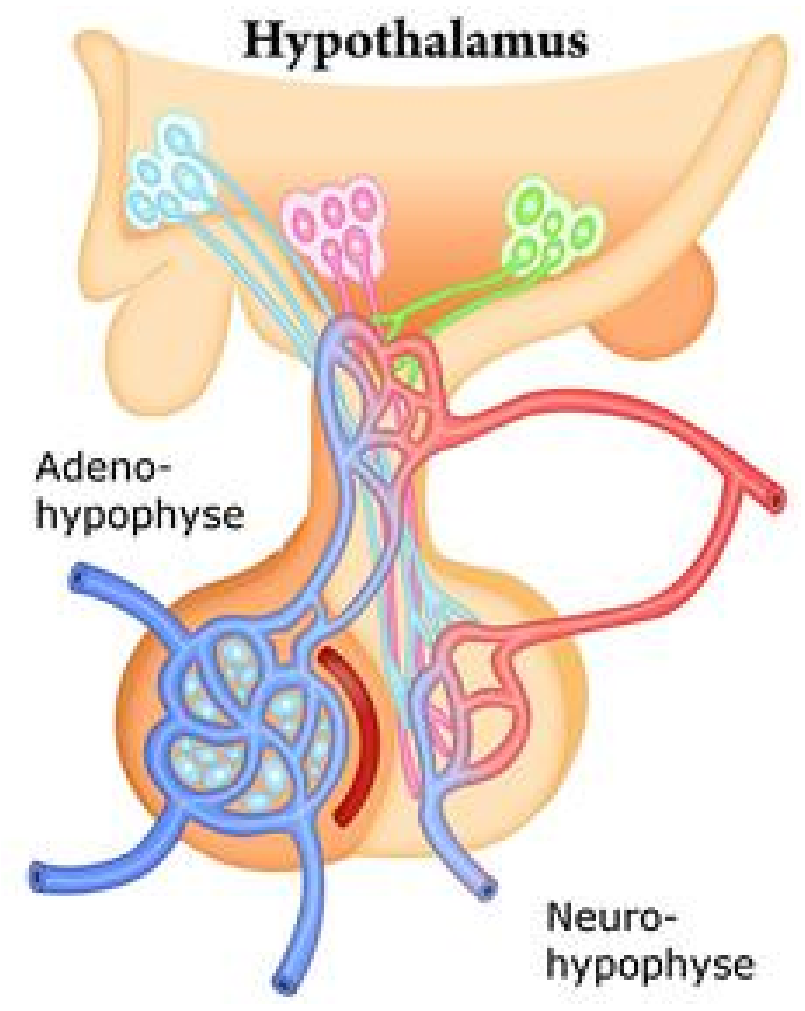

Der Vorderlappen (Adenohypophyse) produziert folgende Hormone:

- Tyreotropin (Thyreoidea-stimulierendes Hormon, TSH): Es regt die Schilddrüse zur Produktion von Schilddrüsenhormon (Thyroxin) an.

- Adrenocorticotropin (Adrenocorticotropes Hormon, ACTH): Es stimuliert die Produktion von Glukokortikoiden.

- Follikel-stimulierendes Hormon (FSH): Es regt in den Geschlechtsorganen die Reifung der Eizellen beziehungsweise die Produktion von Spermien an.

- Luteinisierendes Hormon (LH): Es stimuliert in den Geschlechtsorganen die Produktion und Ausschüttung von Geschlechtshormonen.

- Somatotropin (Somatotropes Hormon, STH, auch Wachstumshormon genannt): Es beeinflusst zahlreiche Stoffwechselvorgänge sowie das Wachstum und die Differenzierung von Zellen. Eine wichtige Wirkung ist zum Beispiel die Regulierung des Körperwachstums nach der Geburt. Diese Wirkung erfolgt über die Anregung der IGF-1-Produktion in der Leber. (Entsprechend wird bei den Hormonuntersuchungen nicht STH, sondern IGF-1 im Blut bestimmt).

- Prolaktin (PRL): Es stimuliert die Milchproduktion in den Brustdrüsen.

- Melanotropin (Melanozyten-stimulierendes Hormon, MSH): Es reguliert u.a. in den Pigmentzellen der Haut (Melanozyten) die Bildung und Verteilung von Pigment (Melanin), das die Haut 
gegenüber UV-Strahlen schützt. Darüber hinaus ist es an der Regulierung von Hunger und sexueller Erregung beteiligt.

Der Hinterlappen (Neurohypophyse) produziert folgende Hormone:

- Oxytocin: Dieses ist zum Ende einer Schwangerschaft und während des Geburtsvorgangs für das Auslösen und die Anpassung der Wehentätigkeit der Gebärmutter zuständig. Im Anschluss an die Schwangerschaft regt die Oxytocin-Ausschüttung die Milchproduktion in den Brustdrüsen an.

- Antidiuretisches Hormon (ADH): Es sorgt dafür, dass nicht zu viel Wasser über die Niere ausgeschieden wird. Außerdem erhöht die ADH-Ausschüttung den Blutdruck, indem sie zu einer Gefäßverengung der Arterien führt.

\subsubsection{Bezug zur Kinderkrebsheilkunde}

Typische Krankheitszeichen bei einer Schädigung des Zwischenhirns, zum Beispiel hervorgerufen durch einen ZNS-Tumor oder durch unerwünschte Nebenwirkungen der Behandlung, sind:

- Halbseitenlähmung

- Gleichgewichtsstörungen

- Appetitregulationsstörungen

- Störungen des Schlaf-Wach-Rhythmus

- Hormonregulationsstörungen (zum Beispiel Wachstums- oder Geschlechtshormonmangel mit entsprechenden Folgen)

- Störungen des Wasserhaushalts (Diabetes insipidus)

- Einklemmungssyndrome (siehe unten)

Unter Einklemmungssydnromen versteht man Verschiebungen von Hirnanteilen, die (zum Beispiel infolge eines Tumors) durch aufgebrauchten Reserveraum und erhöhten Druck in der Schädelhöhle ausgelöst werden. Dabei geht es besonders um die Verschiebung von Großhirnanteilen in Richtung Zwischenhirn und Hirnstamm mit Druckschädigung dieser Strukturen (auch als diencephales Syndrom bezeichnet). Einklemmungssyndrome gehen meist mit Funktionsstörungen des Hirnstamms einher (siehe auch Kapitel "Hirnstamm und Hirnnerven") und führen zu:

- Bewusstseinsstörung und Verhaltensänderung mit Konzentrationsstörungen

- Orientierungsstörungen und im weiteren Verlauf Bewusstseinsverlust

- Atmungsstörungen

- erhöhte Muskelspannung mit gesteigerten Eigenreflexen (siehe auch Kapitel "Rückenmark und Nerven") 
- im fortgeschrittenen Stadium unkontrolliertes Beugen der Arme und Strecken der Beine

- zunächst enge, bei fortschreitender Schädigung mittelweite, manchmal entrundete und lichtstarre Pupillen

- Fehlsteuerungen des vegetativen Nervensystems, das heißt zu schnelle Herztätigkeit (Tachykardie), erhöhter Blutdruck (Hypertonie), zu hohe Körpertemperatur (Hyperthermie) (siehe auch Kapitel "Vegetatives Nervensystem").

Anmerkung: Das Zusammenwirken von Hypothalamus, Hypophyse und den Hormondrüsen des Körpers unterliegt einem Regelkreis, also einem Steuerungssystem mit Gegenkoppelung. Die Intaktheit dieses Regelkreises kann bei Kindern und Jugendlichen mit Krebserkrankungen durch die Erkrankung selbst, jedoch auch durch Nebenwirkungen der Behandlung beeinträchtigt werden.

Aus diesem Grund wird vor und während der Behandlung sowie im Rahmen der Nachsorge regelmäßig anhand von Hormonuntersuchungen überprüft, ob dieser Regelkreis noch intakt ist. Die Auswertung erfolgt in den großen Behandlungszentren durch Kinder-Endokrinologen, also durch Ärzte, die auf den Hormonhaushalt im Kindes- und Jugendalter spezialisiert sind. Gemeinsam mit den Kinder-Endokrinologen werden dann gegebenenfalls notwendige Hormonbehandlungen geplant und überwacht.

Insbesondere bei Patienten mit ZNS-Tumoren im Zwischenhirnbereich (zum Beispiel Gliome im Bereich der Sehbahn) und Hirntumorpatienten, die eine Strahlentherapie im Bereich des Kleinhirns oder des Rückenmarks im Halswirbelsäulenbereich erhalten, kann die Hirnanhangsdrüse und auch die Schilddrüse Strahlung abbekommen und dadurch in ihren Funktionen beeinträchtigt werden. Daher sind diese Hormonuntersuchungen unverzichtbarer Bestandteil der Verlaufs- und Nachsorgeuntersuchungen.

\subsubsection{Das Kleinhirn (Cerebellum)}

Ein Großteil der ZNS-Tumoren im Kindes- und Jugendalter, zum Beispiel Astrozytome und Medulloblastome, wachsen im StrahlentherapieKleinhirn. Der Aufbau und die Aufgaben des Kleinhirns sowie die Entstehung typischer Krankheitszeichen von Tumoren in diesem Bereich werden im Folgenden dargestellt.

\subsubsection{Aufbau des Kleinhirns}

Das Kleinhirn liegt in der hinteren Schädelgrube [siehe hintere Schädelgrube]. Seine obere Fläche wird vom Großhirn überdeckt, von dem es durch das Kleinhirnzelt (Tentorium cerebelli) getrennt ist. In die untere Fläche des Kleinhirns ist das verlängerte Mark eingelagert, das zum Hirnstamm gehört (siehe auch Kapitel "Hirnstamm und Hirnnerven").

Das Kleinhirn besteht aus den beiden Kleinhirnhälften (Kleinhirnhemisphären) und dem Kleinhirnwurm (Vermis cerebelli). Es ist beidseits durch die Kleinhirnstiele mit dem Hirnstamm verbunden. Durch diese verlaufen alle auf- und absteigenden Nervenfaserbahnen.

Im Längsschnitt erinnern die Kleinhirnstrukturen an Verästelungen eines Laubbaums. Sie werden deshalb auch Lebensbaum genannt. Dabei bildet die graue Substanz die 
aus drei Nervenzellkernschichten bestehende Kleinhirnrinde (Körnerschicht, Purkinje-Schicht, Molekularschicht). Die weiße Substanz führt verschiedene Faserbahnen und bildet das Kleinhirnmark.

Tief im Mark liegen wiederum Gruppen von Nervenzellkernen, die Kleinhirnkerne. Diese sind selbständige Schaltzentren, die Impulse erhalten und weitergeben. Jede Erregungsweiterleitung wird von der Kleinhirnrinde durch fein abgestimmte Hemmung und Enthemmung reguliert.

\subsubsection{Funktionen des Kleinhirns}

Das Kleinhirn ist das Kontrollorgan für das Zusammenwirken von Muskelbewegungen (Koordination), für die Feinabstimmung von Bewegungsabläufen und für die Regulierung der Muskelspannung. Aufgrund seines Aufbaus sowie funktioneller Gegebenheiten unterscheidet man beim Kleinhirn drei verschiedene Anteile oder Funktionsbereiche:

a. Vestibulocerebellum: Das Vestibulocerebellum beeinflusst die Köperhaltung und die Feinabstimmung von Augenbewegungen. Über die zugehörigen aufsteigenden (afferenten) Nervenfaserbahnen erhält es Informationen vom Gleichgewichtsorgan im Innenohr, die es dann über die absteigenden (efferenten) Bahnen zu den beiden Kernen des Gehör- und Gleichgewichtsnervs beziehungsweise zu den Augenmuskelnervenkernen im Hirnstamm weiterleitet (siehe auch Kapitel "Hirnstamm und Hirnnerven", Abschnitte zum Mittelhirn und zum VIII. Hirnnerv).

b. Spinocerebellum: Das Spinocerebellum wird hauptsächlich durch den Kleinhirnwurm gebildet. Aus dem Rückenmark erhält es Nachrichten über die Stellung von Armen, Beinen, Rumpf sowie über die Muskelspannung. Diese Informationen werden in verschiedene Nervenzellkerngebiete des Hirnstamms weitergeleitet.

c. Pontocerebellum: Die beiden Kleinhirnhemisphären bilden das Pontocerebellum. Es erhält Informationen von der Brücke im Hirnstamm (siehe auch Kapitel "Hirnstamm und Hirnnerven") und leitet diese zum Mittelhirn und zum Thalamus (siehe auch Kapitel "Zwischenhirn").

\subsubsection{Bezug zur Kinderkrebsheilkunde}

Störungen von Kleinhirnfunktionen können beispielsweise bei Kindern und Jugendlichen durch einen Tumor in der hinteren Schädelgrube [hintere Schädelgrube] verursacht werden und führen unter anderem zu folgenden Krankheitszeichen:

- Gleichgewichtsstörungen: schwankendes Gangbild ("wie betrunken"), Haltungsstörungen (Ataxie)

- überschießende Zielbewegungen (Dysmetrie)

- ungeordnete Bewegungen bei einem normalerweise schnell erfolgenden Bewegungsablauf, der aus zwei entgegengesetzten Bewegungen besteht, wie zum Beispiel das Eindrehen einer Glühbirne (Dysdiadochokinese)

- Zittern der Gliedmaßen während einer zielgerichteten Bewegung, meist der Hände (Intentionstremor) 
- langsame, abgehackte, verwaschene Sprache (skandierende Sprache)

- Blickrichtungs-, Blickhaltungsstörungen im Sinne von rhythmisch verlaufenden Augenbewegungen (Nystagmus)

- niedrige Muskelspannung (Muskelhypotonie)

- Schwindel

- Veränderungen der Handschrift ("in den Keller schreiben")

\subsubsection{Hirnstamm und Hirnnerven}

Als Hirnstamm bezeichnet man die Abschnitte des Gehirns, die sich unterhalb des Zwischenhirns befinden und die den Übergang zwischen Gehirn und Rückenmark bilden.

Durch diesen Abschnitt soll vor allem besser nachzuvollziehen sein, welche Krankheitszeichen durch einen Tumor in diesem Teil des Zentralnervensystems entstehen können und warum die meisten Hirnstammtumoren noch immer schwierig zu behandeln sind.

\section{Der Hirnstamm besteht aus}

a. Mittelhirn (Mesencephalon)

b. Brücke (Pons)

c. verlängertem Mark(Medulla oblongata)

Außerdem liegen im Hirnstamm die Ursprungsorte der zwölf Hirnnervenpaare, die Hirnnervenkerne. In einem Hirnnervenkern entspringen die Fasern, die Erregungen unter anderem zu verschiedenen Muskeln im Kopf- und Halsbereich weiterleiten. Gleichzeitig kommen in diesen Kernen die Nachrichten aus den Regionen an, die von den entsprechenden Hirnnerven versorgt werden.

\subsubsection{Mittelhirn (Mesencephalon)}

Das Mittelhirn ist nach oben durch das Zwischenhirn und nach unten durch die Brücke begrenzt. Es besteht aus:

- den Großhirnschenkeln (Crura cerebri): Durch diese verlaufen wichtige, zwischen Gehirn und Rückenmark auf- und absteigende Bahnen.

- der Mittelhirnhaube (Tegmentum mesencephali): Dort befinden sich große Ansammlungen von Nervenzellkörpern für Muskelaktivitäten (zum Beispiel Substantia nigra, Nucleus ruber) und für den III. und IV. Hirnnerv (Augenmuskelnerven).

- dem Mittelhirndach (Tectum mesencephali): Dieses besteht aus einer dünnen, hügeligen Gewebeplatte aus Nervenfasern (Vierhügelplatte), die sowohl Anteile der Sehbahn als auch der Hörbahn enthält. 


\subsection{Bezug zur Kinderkrebsheilkunde}

Für eine Hirnstammschädigung durch einen Tumor im Bereich des Mittelhirns sprechen unter anderem:

- Schielstellung der Augen

- Unfähigkeit, die Augäpfel nach oben oder nach unten zu richten (vertikale Blicklähmung)

- mittelweite, manchmal entrundete Pupillen

- Bewegungsstörungen, Gangstörungen

- Störungen der Atemtätigkeit

- Konzentrationsstörungen, Bewusstseinsstörungen

\subsubsection{Brücke (Pons)}

Die Brücke ist nach unten durch das verlängerte Mark, nach oben durch das Mittelhirn und nach hinten durch das Kleinhirn begrenzt. Sie enthält die Nervenzellkörper für den V. bis VIII. Hirnnerv (siehe unten) sowie Teile des Atem-, Kreislauf- und Aktivitätszentrums. Die Brücke erhält zudem verschiedene Informationen aus dem Hörorgan und dem Gesicht, die sie über verschiedene Nervenfaserbahnen an das Kleinhirn weiterleitet.

\subsection{Bezug zur Kinderkrebsheilkunde}

Für eine Hirnstammschädigung durch einen Tumor im Bereich der Brücke sprechen unter anderem:

- Schielstellung der Augen

- Lähmung des Gesichtsnervs / Herabhängen einer Gesichtshälfte

- Blickrichtungsstörungen

- Lähmung von beiden Armen und beiden Beinen (komplette Querschnittslähmung)

- unregelmäßige Atemtätigkeit

- Bewusstseinsstörungen

- Verlust der Willkürmotorik (außer Augen- und Lidbewegungen) bei erhaltenem Bewusstsein (Locked-in-Syndrom)

\subsubsection{Verlängertes Mark (Medulla oblongata)}

Das verlängerte Mark geht nach unten direkt ins Rückenmark und nach oben in die Brücke über. Nach hinten ist es vom Kleinhirn überdeckt. In seinem hinteren Anteil befinden sich die Ursprungsorte für den IX. bis XII. Hirnnerv (siehe unten). In seinem vorderen Anteil verdickt sich die größte vom Gehirn durch das Rückenmark absteigende Nervenbahn mit den Erregungsleitungen für die Muskelantworten, die Pyramidenbahn, zu den Pyramiden. Außerdem liegen im verlängerten 
Mark Gruppen von Nervenzellen, die mit den anderen Hirnstammanteilen das Atem- und Kreislaufzentrum bilden.

\subsection{Bezug zur Kinderkrebsheilkunde}

Für eine Hirnstammschädigung durch einen Tumor im Bereich des verlängerten Marks sprechen beispielsweise:

- abgeschwächter oder fehlender Würge- und Hustenreflex

- weite Pupillen

- Schiefhals

- Sprechstörungen und Zungenlähmung

- Lähmung einer Körperhälfte (auf der Gegenseite der Schädigung)

- Atmungs- und Kreislaufstörungen

\subsubsection{Hirnnerven}

Es gibt insgesamt zwölf Hirnnervenpaare. Sie sind, mit einer Ausnahme (N. vagus), in ihrem Verlauf und Versorgungsgebiet auf den Kopf-Hals-Bereich beschränkt und werden traditionell mit römischen Ziffern nummeriert (I-XII).

Bei den ersten beiden Hirnnerven (I und II) handelt es sich um Gehirnanteile, bei den übrigen zehn (III-XII) jeweils um Nervenpaare des peripheren Nervensystems (peripheres Nervensystem, siehe auch "Einführung zum Nervensystem"). Die Ursprungsorte (Hirnnervenkerne) der Hirnnerven I und II liegen im Großhirn beziehungsweise im Zwischenhirn. Die Ursprungsorte der übrigen Hirnnervenpaare befinden sich meist in Mittelhirn, Brücke oder verlängertem Mark, also im Hirnstamm. Sie sind hauptsächlich für die Gefühlsempfindungen, Sinneswahrnehmungen und die Muskeln im Kopf- und Halsbereich zuständig.

Anmerkung: Im Folgenden erfolgt eine Beschreibung von Verlauf und Funktion der einzelnen Hirnnerven. Bitte beachten Sie dabei, dass alle Hirnnerven paarig, das heißt, beidseitig angelegt sind.

\subsection{Hirnnerv: Der Riechnerv (Nervus olfactorius)}

Der Riechnerv (Nervus olfactorius) ist für die Geruchswahrnehmung zuständig. Er setzt sich aus gebündelten Fortsätzen der Sinneszellen in der Riechschleimhaut der Nase zusammen. Der Riechnerv zieht von der Nasenhöhle zum Riechkolben (Bulbus olfactorius), einer Gehirnausstülpung im vorderen Bereich der Schädelhöhle.

\section{Bezug zur Kinderkrebsheilkunde}

Bestrahlungen und verschiedene Tumoren, zum Beispiel Weichteilsarkome des Kopf- und Halsbereichs oder große ZNS-Tumoren im Bereich des vorderen Großhirns, können durch Schädigung des Riechkolbens die Geruchswahrnehmung des Patienten beeinträchtigen. 


\subsection{Hirnnerv: Der Sehnerv (Nervus opticus)}

Der Sehnerv (Nervus opticus) ist eine Leitungsbahn des Gehirns, die für das Sehen zuständig ist. Er entspringt in der Netzhaut und tritt durch einen kleinen knöchernen Kanal aus der Augenhöhle in die Schädelhöhle ein. Im weiteren Verlauf bildet er mit dem Sehnerv der Gegenseite die Sehnervenkreuzung (Chiasma opticum).

Von hier an nennt man den Sehnervenfaserzug zunächst "Tractus opticus". Er zieht weiter durch Mittel- und Zwischenhirn und geht dann als "Sehstrahlung" in die Sehrinde über, welche sich im Hinterhauptslappen des Großhirns befindet (siehe auch Kapitel "Großhirn").

\section{Bezug zur Kinderkrebsheilkunde}

In der Kinderkrebsheilkunde spielt der Sehnerv unter anderem insofern eine wichtige Rolle, als dass er zum Beispiel durch bestimmte Tumoren, beispielsweise ein Retinoblastom oder ein niedriggradig malignes Gliom, geschädigt werden kann. Die Schädigung kann entweder direkt durch den Tumor erfolgen oder auch indirekt durch einen länger bestehenden erhöhten Druck in der Schädelhöhle, der ebenfalls tumorbedingt ist.

Typischerweise können niedriggradig maligne Gliome bei Kindern mit Neurofibromatose Typ 1 (NF1) im Bereich der gesamten Sehbahn vorkommen. Sie werden deshalb auch Opticusgliome genannt.

In Kenntnis des Sehbahnverlaufs kann man sich nun bestimmt besser vorstellen, dass ein Tumor, eine Operation / Tumorentfernung oder auch eine Strahlentherapie im Bereich der Sehbahn immer mit dem hohen Risiko einhergeht, dass der Patient die Sehfähigkeit eines Auges verliert. Tumoren, die nahe der Sehnervenkreuzung liegen oder sogar von ihr ausgehen, sind in diesem Zusammenhang besonders gefährlich, denn hier sind die Nervenfasern beider Augen von einer möglichen Schädigung betroffen. Daher ist die Erstellung einer für den Patienten optimalen Behandlungsstrategie oft sehr schwierig.

Der Sehnerv spielt auch bei der Hirntumor-Diagnostik eine wichtige Rolle: Bei der Augenhintergrundspiegelung wird der Sehnerv untersucht, genauer gesagt, der Bereich der Netzhaut, aus dem er entspringt (Sehnervenpapille). Wölbt sich die Papille in die Augenhöhle hinein, so lässt das auf einen erhöhten Druck hinter der Papille und somit in der Schädelhöhle schließen (beispielsweise ausgelöst durch einen Hirntumor).

\subsection{Hirnnerv: Augenmuskelnerv (Nervus oculomotorius)}

Der Augenmuskelnerv (Nervus oculomotorius) ist zusammen mit dem IV. Hirnnerv (Nervus trochlearis) und dem VI. Hirnnerv (Nervus abducens) für die Bewegung der Augenmuskeln und damit für die Bewegung des Augapfels zuständig. Außerdem sendet er Nervenäste zu dem Muskel, der das Oberlid hebt sowie zu dem Muskel, der für die Nah- und Ferneinstellung der Augenlinse (Akkomodation) sorgt.

Der Augenmuskelnerv enthält außerdem spezielle Fasern, die - zusammen mit dem Sehnerv - für die Lichtreaktion der Pupillen, das heißt für die Engstellung der Pupillen (Miosis) bei Lichteinstrahlung, verantwortlich sind. Der III. Hirnnerv entspringt im Mittelhirn, zieht nach vorne und im Bereich der Hirnanhangsdrüse (Hypophyse) in die Schädelhöhle und dann weiter in die Augenhöhle. Dort teilt er sich in seine Äste auf. 


\section{Bezug zur Kinderkrebsheilkunde}

Ein ZNS-Tumor, der den III. Hirnnerv in seinem Ursprung- und/oder Verlauf behindert, kann zum Funktionsausfall führen. Dann überwiegen für die Bewegung des Augapfels diejenigen Augenmuskeln, die von den intakten Augenmuskelnerven versorgt werden, während die, für die der III. Hirnnerv zuständig ist, gelähmt sind.

Dies führt zu einer typischen Schielstellung: Der Augapfel des betroffenen Auges ist nach außen und unten gerichtet und die Patienten klagen über Doppelbilder. Außerdem kommt es zur Lähmung des Augenlidmuskels und dadurch zum Herunterhängen des Augenlides (Ptosis).

Die Schädigung der Fasern für die Lichtreaktion (siehe oben) führt zum Überwiegen des Muskels, der für die Pupillenerweiterung zuständig ist. Dadurch kommt es zu einer sehr weiten Pupille (Mydriasis). Außerdem ist keine Nah- oder Ferneinstellung der Augenlinse (Akkomodation) mehr möglich - der Patient sieht dann unscharf.

Wird der N. oculomotorius hauptsächlich in seinem Ursprungsbereich, dem Mittelhirn, geschädigt - beispielsweise durch einen Tumor (zum Beispiel einem Tectumgliom) im Bereich des Mittelhirndachs (Vierhügelplatte; siehe Abschnitt "Mittelhirn") - so können Mydriasis (weite Pupille) und unscharfes Sehen zusätzlich von einer Blicklähmung begleitet sein, bei der beide Augäpfel nur noch geradeaus oder seitwärts, das heißt, nicht mehr nach oben oder unten gerichtet werden können (Parinaud-Syndrom).

Außerdem kann der Hirnstamm, zum Beispiel durch einen tumorbedingt erhöhten Druck in der Schädelhöhle, nach unten gegen den Schädelknochen gedrückt werden. Dies kann dazu führen, dass auch der III. Hirnnerv in seinem Verlauf gegen eine knöcherne Struktur im Bereich des Hirnstamms (Klivuskante) gedrückt wird. Die dadurch verursachte schnell zunehmende Bewusstseinseinschränkung mit Pupillenerweiterung ist ein Alarmzeichen und deutet auf eine dramatische, lebensbedrohliche Zustandsverschlechterung des Patienten hin (Klivuskantensyndrom).

\subsection{Hirnnerv (Nervus trochlearis)}

Der IV. Hirnnerv (Nervus trochlearis) ist, ebenso wie der III. und der VI. Hirnnerv, an der Bewegung des Augapfels beteiligt. Er zieht etwas hinter und seitlich des III. Hirnnervs vom Mittelhirn in die Augenhöhle.

\section{Bezug zur Kinderkrebsheilkunde}

Wird der IV. Hirnnerv geschädigt, so kommt es durch das Überwiegen der von den noch intakten Augenmuskelnerven versorgten Muskeln zu einer Schielstellung, bei der der Augapfel nach oben und zur Nase hin gerichtet ist.

\subsection{Hirnnerv (Nervus trigeminus)}

Der V. Hirnnerv (Nervus trigeminus) ist ein großer Nerv mit vielen Aufgaben. Er entspringt am Seitenrand der Brücke und zieht dann in den vorderen Bereich der Schädelhöhle, wo er sich in seine drei Endäste aufteilt:

- Der Nervus ophthalmicus gelangt mit dem III. Hirnnerv in die Augenhöhle und teilt sich dort in weitere Äste auf. Diese sind für den Nachrichtendienst der gesamten Augenhöhle, der Haut der 
Stirn, der Schleimhaut der Nasenscheidewand sowie, zusammen mit dem Gesichtsnerv (VII. Hirnnerv - Nervus facialis), der Tränendrüse zuständig sind.

- Der Nervus maxillaris sendet Äste zur Augenhöhle, zur Schläfe, zum Gaumen, zur Wange, zur Oberlippe und zu Zahnfleisch und Zähnen des Oberkiefers.

- Der Nervus mandibularis führt Äste für die Kaumuskulatur sowie zum Trommelfell, zur Haut des äußeren Gehörgangs, für die Gefühlsempfindung in den vorderen zwei Dritteln der Zunge, zur Unterlippe und zu Zahnfleisch und Zähnen des Unterkiefers. Zusammen mit dem Gesichtsnerv (VII. Hirnnerv - Nervus facialis) versorgt er außerdem die Ohrspeicheldrüse und die Speicheldrüsen im Mund.

Außerdem ist der V. Hirnnerv für den Kornealreflex verantwortlich. Dieser wird durch leichtes Berühren der Augen-Hornhaut (zum Beispiel mit einem Wattestäbchen) ausgelöst; es kommt zu Lidschluss und einer Aufwärtsbewegung des Augapfels.

\section{Bezug zur Kinderkrebsheilkunde}

Der V. Hirnnerv kann im Rahmen einer, meist behandlungsbedingten, Immunsuppression von einer Infektion mit dem Varizella-Zoster-Virus betroffen sein.

\subsection{Hirnnerv: Augenmuskelnerv (Nervus abducens)}

Der Augenmuskelnerv (Nervus abducens) ist zusammen mit dem III. Hirnnerv (Nervus oculomotorius) und dem IV. Hirnnerv (Nervus trochlearis) für die Bewegung der Augenmuskeln und damit für die Bewegung des Augapfels zuständig. Seine Fasern entspringen in der Brücke, an deren Unterrand sie aus dem Hirnstamm austreten. Von dort ziehen sie zur vorderen Schädelgrube, wo sie mit dem III. Hirnnerv in die Augenhöhle eintreten. Der VI. Hirnnerv versorgt den Augenmuskel, der den Augapfel zur Seite zieht.

Bezug zur Kinderkrebsheilkunde:

Der Augenmuskelnerv kann zum Beispiel durch einen Hirntumor im hinteren Bereich der Schädelhöhle (beispielsweise einem Kleinhirn-Astrozytom oder einem Medulloblastom) oder auch durch eine (meist) vorübergehende Störung nach einer Operation in diesem Bereich geschädigt werden. Bei einer solchen Schädigung ist der betroffene Augapfel nach innen, also zur Nase hin gerichtet. Der Patient schielt und sieht doppelt.

\subsection{Hirnnerv: Gesichtsnerv (Nervus facialis)}

Dieser große Nerv enthält alle Typen von Nervenfasern (für Gefühlsempfindungen, Muskelbewegungen, vegetative Funktionen). Sie entspringen in der Brücke, treten an deren Unterrand aus dem Hirnstamm aus und ziehen dann in einen knöchernen Kanal im Schläfenbein (Canalis facialis). In diesem Kanal werden zwei Nervenäste für die Versorgung von Mittel- und Innenohr (Nervus intermedius und Nervus stapedius) abgegeben.

Nach dem Austritt aus seinem Kanal verläuft der VII. Hirnnerv unterhalb der Ohrspeicheldrüse weiter nach vorne bis zum Hinterrand des Unterkiefers, wo er unter anderem Äste abgibt zur Versorgung eines Großteils der Gesichtsmuskulatur, der Ohrmuskeln, einiger Augenlidmuskeln (zum Beispiel den Muskel für den Lidschluss), der Geschmacksempfindung in den vorderen zwei Zungendritteln, der Tränendrüse, der Speicheldrüsen und einem großen Halsmuskel. 
Bezug zur Kinderkrebsheilkunde:

Bei einer Schädigung des VII. Hirnnervs unterscheidet man abhängig vom Ort der Schädigung zwei unterschiedliche Lähmungstypen:

- Bei der "peripheren Fazialisparese" ist die Schädigung des Nervs in seinem Verlauf (zum Beispiel durch einen Tumor oder durch Infektionen im Mittelohr) erfolgt. Es kommt zu einer schlaffen Lähmung aller Muskeln auf der betroffenen Gesichtshälfte (die Mundpartie hängt herab, das Auge kann nicht mehr geschlossen werden). Zudem treten auch Störungen des Augentränens, des Speichelflusses und der Geschmacksempfindung auf. In manchen Fällen kann die Erregbarkeit der Hörnerven herabgesetzt sein; der Patient hört dann "zu laut".

- Die "zentrale Fazialisparese" wird durch eine Schädigung im Großhirn verursacht, genauer gesagt, in einem Bereich in der Großhirnrinde (siehe auch Kapitel "Großhirn"), der für die Erregungen im Gesichtsbereich zuständig ist. Anders als bei der peripheren Fazialisparese können die Stirn gerunzelt und das Auge geschlossen werden.

\subsection{Hirnnerv: Gehör- und Gleichgewichtsnerv (Nervus vestibulocochlearis oder Nervus statoacusticus)}

Der VIII. Hirnnerv ist aus zwei Komponenten zusammengesetzt: den Nervenbahnen für das Hörorgan und denen für das Gleichgewichtsorgan. Er führt hauptsächlich aufsteigende (afferente) Fasern.

Diese übertragen zum einen die Erregungen aus dem Innenohr zum Hirnstamm auf die Hörbahn und weiter zur Hörrinde des Großhirns (siehe auch "Das Großhirn"), zum anderen auf die Gleichgewichtsbahn zum Kleinhirn sowie auch zu den Ursprungsorten der Augenmuskelnerven (siehe auch: III., IV. und VI. Hirnnerv). Dadurch werden besonders Gleichgewicht, aufrechte Haltung, Kopfbewegungen und das Festhalten des Blickes bei Bewegungen kontrolliert.

\section{Bezug zur Kinderkrebsheilkunde}

Bei Kindern und Jugendlichen mit Kleinhirntumoren (zum Beispiel bestimmten niedriggradig malignen Gliomen oder einem Medulloblastom) sind die oben beschriebenen Körperfunktionen oft gestört.

\subsection{Hirnnerv: Zungen-Rachennerv (Nervus glossopharyngeus)}

Der XI. Hirnnerv entspringt im verlängerten Mark (Medulla oblongata) des Hirnstamms. Von dort zieht er zum Zungengrund, wo er sich in seine Endäste aufteilt. Diese sind für Gefühlsempfindungen im Mittelohr, Teile der Ohrspeicheldrüse, Zungen- und Schlundmuskulatur, Gaumensegel, Drüsen und Schleimhaut des Rachens, für den Blutdruck-Sensor an der Karotis-Arterie (Glomus caroticum) und letztlich für die Geschmacks- und Gefühlsempfindung des hinteren Zungendrittels und den Würgereflex zuständig.

Der Zungen-Rachennerv fällt selten allein aus, sondern gemeinsam mit dem X. und dem XI. Hirnnerv, die gemeinsam mit inm die Schädelhöhle verlassen.

Bezug zur Kinderkrebsheilkunde

Bei Schädigungen des Zungen-Rachennerves kann es zum Ausfall des Würgereflexes, zu Störungen der Geschmacksempfindung und zu einer Abweichung des Gaumensegels 
zur gesunden Seite hin (denn Muskelkraft der gesunden Seite überwiegt nun) sowie zu Schluckstörungen kommen.

Als Ursachen kommen sämtliche Schädigungen im verlängerten Mark, beispielsweise durch einen Hirnstammtumor oder durch erhöhten Druck in der Schädelhöhle, in Frage.

\subsection{Hirnnerv (Nervus vagus)}

Der X. Hirnnerv (Nervus vagus) nimmt seinen Ursprung im verlängerten Mark des Hirnstamms. Seine Fasern verlassen gemeinsam mit dem IX. und dem XI. Hirnnerv die Schädelhöhle. Der N. vagus ist der größte Nerv des Parasympathicus [siehe parasympathisches Nervensystem] und der wichtigste Gegenspieler des Sympathicus [siehe sympathisches Nervensystem].

Er versorgt nicht nur den Kopfbereich wie die übrigen Hirnnerven, sondern steigt in den Brust- und Bauchraum ab, wo er sich in den Eingeweiden (Herz, Atmungsorgane, Verdauungsorgane bis zum Dickdarm) netzartig verzweigt.

Im Kopf- und Halsbereich versorgen seine Äste unter anderem Ohrmuschel und äußeren Gehörgang, die harte Hirnhaut, die Schleimhaut von Kehlkopf und Luftröhre und die Kehlkopfmuskeln. In diesem Bereich wird er auch Nervus phrenicus genannt. (Weitere Informationen zu Parasympathicus und Sympathicus erhalten Sie im Kapitel "Vegetatives Nervensystem".)

\section{Bezug zur Kinderkrebsheilkunde}

Große Tumoren im Halsbereich (Mediastinaltumoren, wie zum Beispiel bestimmte Lymphome) können zu einer Schädigung des X. Hirnnervs im Halsbereich führen. Die Patienten sind wegen der daraus folgenden Stimmbandlähmung heiser (Phrenicuslähmung).

\subsection{Hirnnerv (Nervus accessorius)}

Der XI. Hirnnerv (Nervus accessorius) führt nur absteigende (efferente) Fasern zu verschiedenen Schlund- und Halsmuskeln. Einige seiner Fasern entspringen im verlängerten Mark des Hirnstamms und verlaufen gemeinsam mit dem X. Hirnnerv, andere entspringen in den ersten sechs Halssegmenten im Rückenmark.

\section{Bezug zur Kinderkrebsheilkunde}

Wenn dieser Nerv durch einen Rückenmarkstumor im Bereich der Halswirbelsäule oder im unteren Hirnstamm geschädigt ist, kommt es zu einer Schiefhaltung des Kopfes (Schiefhals). Außerdem kann der Arm der betroffenen Seite nicht mehr über die Schulter hinaus gehoben werden.

\subsection{Hirnnerv: Zungennerv (Nervus hypoglossus)}

Der XII. Hirnnerv (Zungennerv) ist wie der XI. Hirnnerv ein rein motorischer Nerv. Er entspringt ebenfalls im verlängerten Mark und ist für die Versorgung der Zungenmuskulatur, also für die Zungenbewegungen zuständig.

\section{Bezug zur Kinderkrebsheilkunde}

Bei einer einseitigen Schädigung des XII. Hirnnervs, zum Beispiel durch einen Hirnstammtumor, kommt es zu einer halbseitigen Zungenlähmung mit Abweichen der Zunge zur gesunden Gegenseite, deren Muskeln nun vergleichsweise stärker ziehen. 
Ist der Zungennerv beidseitig geschädigt, beispielsweise durch einen großen Hirnstammtumor oder aber eher noch durch einen Tumor im Bereich des Zungenversorgungsgebietes in der Großhirnrinde (siehe auch Kapitel "Großhirn"), dann kann es zu einer kompletten Zungenlähmung kommen, das heißt, die Zunge kann nicht mehr bewegt werden. Auf diese Weise entstehen schwere Sprechstörungen und eine Behinderung der Nahrungsaufnahme.

\subsubsection{Mögliche Ursachen für Störungen von Hirnstamm- und Hirnnervenfunktionen}

In der Kinderkrebsheilkunde kommen vor allem die im Folgenden aufgeführten Ursachen für eine Schädigung des Hirnstamms und damit auch der Hirnnerven in Frage. (Typische Krankheitszeichen bei Hirnstamm- und/oder Hirnnervenschädigungen sind jeweils in den Abschnitten "Mittelhirn", "Brücke", "verlängertes Mark" und "Hirnnerven" unter "Bezug zur Kinderkrebsheilkunde" beschrieben.)

\subsection{Erhöhter Druck im Schädelinneren}

Das Gehirn ist nach außen durch den knöchernen Schädel begrenzt. Das Großhirn liegt unten und hinten dem Kleinhirnzelt (Tentorium cerebelli) auf, welches das gesamte Kleinhirn überspannt und nur eine einzige Öffnung für die Verbindung zum Hirnstamm besitzt (Tentoriumschlitz).

Wenn also ein wachsender Tumor im Bereich des Großhirns dessen Reserveräume ausgeschöpft hat, kann das Gehirn den dadurch ansteigenden Druck im Schädelinneren nicht mehr abpuffern. Es kommt dann, entweder ein- oder beidseitig, zu einer lebensbedrohlichen Massenverschiebung von Großhirnanteilen nach unten und folglich zu deren Einklemmung im Schlitz des Kleinhirnzeltes. Dadurch erfährt der Hirnstamm einen starken Druck, der dramatische Folgen für den Patienten haben kann, wenn die klinischen Veränderungen nicht rechtzeitig erkannt und entsprechend behandelt werden.

\subsection{Kleinhirntumoren}

Kleinhirntumoren wie das Medulloblastom oder das Kleinhirn-Astrozytom können nach einer Ausschöpfung der Reserveräume eine Massenverschiebung mit Einklemmung von Kleinhirnanteilen von unten nach oben in den Tentoriumschlitz verursachen.

Ein sehr großer Tumor in dieser Region kann zusätzlich dazu führen, dass Kleinhirnanteile nach unten auf den Hirnstamm gedrückt werden, der dann in der knöchernen Schädelöffnung zum Wirbelkanal (Foramen occipitale magnum) einklemmt. Diese Gefahr wird verstärkt, wenn durch eine Lumbalpunktion der Druck im Rückenmarkskanal gesenkt wird und sich dadurch der Druckunterschied zwischen Schädelhöhle und Rückenmarkskanal noch weiter vergrößert. Hierdurch kann sich in kürzester Zeit ein Atemstillstand entwickeln.

Deshalb werden bei den betroffenen Patienten immer erst bildgebende Untersuchungen [siehe bildgebende Verfahren] durchgeführt, mittels derer das Ausmaß des Tumors abgeschätzt werden kann. Besteht die Gefahr einer Einklemmung, ist die sofortige Tumorentfernung notwendig.

\subsection{Hirnstammtumoren}

Etwa 10 bis $20 \%$ der ZNS-Tumoren im Kindes- und Jugendalter sind Hirnstammtumoren, bei denen es sich meist um siehe Gliome handelt. 
Circa $20 \%$ der Hirnstammgliome wachsen, indem sie das Gewebe verdrängen (exophytisches Wachstum) und verlängertes Mark, Brücke und Mittelhirn in erster Linie durch Druck auf diese Strukturen schädigen. Die verbleibenden $80 \%$ wachsen infiltrierend, das heißt in das Hirnstammgewebe hinein (intrinsisches Wachstum). Dadurch werden nach und nach sämtliche Hirnstammstrukturen zerstört.

Exophytische Tumoranteile können in manchen Fällen operativ entfernt werden, während intrinsisch wachsende Hirnstammgliome sehr schwer zu behandeln sind.

Anmerkung: Die frühzeitige Erfassung und Behandlung der drohenden oder bereits erfolgenden Einklemmung sind ein Ergebnis lückenloser Überwachung mit regelmäßigen körperlichen Verlaufsuntersuchungen durch ein spezialisiertes Behandlungsteam und entscheidend für die Prognose des Patienten.

\subsubsection{Lagebeschreibungen von Hirnstrukturen und von Tumoren im Gehirn}

Für viele Gespräche mit Ihrem Behandlungsteam ist es bestimmt von Vorteil zu wissen, dass Ausdrücke wie" oben - unten" oder "vorn - hinten" bei der Lagebeschreibung von Hirnstrukturen ungenau sind. Die vom Fachpersonal häufig benutzten Bezeichnungen lauten deshalb:

- rostral (oder oral): am Vorderende der Achse (von -rostrum-: Schiffsschnabel bzw. von -os-: Mund)

- kaudal: am hinteren Ende der Achse (von -cauda-: Schwanz)

- basal (oder: ventral): Unterseite (von -venter-: Bauch)

- dorsal: Oberseite (von -dorsum-: Rücken)

Außerdem wird eine bestimmte anatomische Struktur, das Kleinhirnzelt (Tentorium cerebelli), besonders von den Neurochirurgen regelmäßig für Lagebeschreibungen von ZNS-Tumoren verwendet.

Das Tentorium cerebelli ist eine Erweiterung der harten Hirnhaut [siehe Hirnhäute], die das Kleinhirn wie ein Zelt von den hinteren Anteilen des Großhirns abgrenzt. Entsprechend liegen manche ZNSTumoren supratentoriell, das heißt oberhalb des Tentoriums, oder infratentoriell, also unterhalb des Tentoriums.

\subsubsection{Das Rückenmark (Medulla spinalis) und seine Nerven}

Dieser Abschnitt soll eine Übersicht über den Aufbau und die Aufgaben des Rückenmarks geben und aufzeigen, wie es mit den anderen Teilen des Nervensystems zusammenarbeitet. So lässt sich beispielsweise leichter verstehen, wie bestimmte Arten von Lähmungen entstehen, welche wichtigen Informationen der Arzt bei der klinischen Untersuchung durch das Klopfen mit dem Reflexhammer erhält, und warum der Neurochirurg bestimmte Rückenmarkstumoren nicht operiert. 


\subsubsection{Aufbau des Rückenmarks}

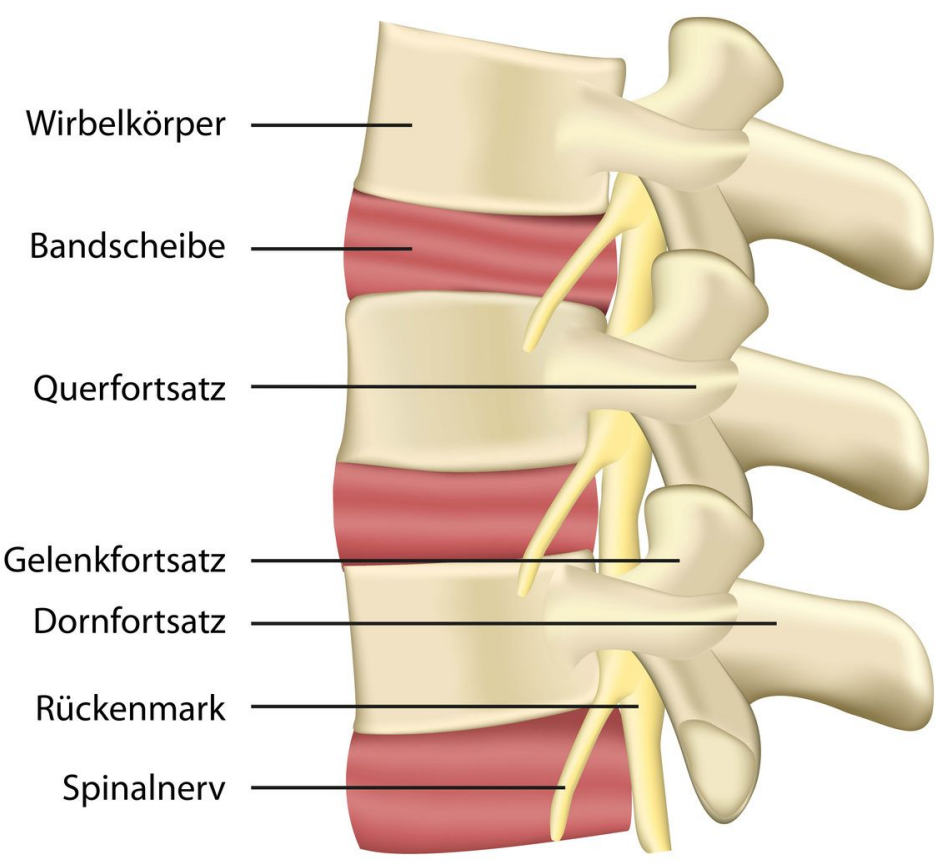

Das Rückenmark ist von Gehirn-Rückenmark-Flüssigkeit (Liquor) und den drei Rückenmarkshäute umgeben: der harten Rückenmarkshaut (Dura mater), der Spinngewebshaut (Arachnoidea) und der weichen Rückenmarkshaut (Pia mater) (siehe auch Einführungsseite zu Kapitel "Das ZNS").

Am unteren Ende verjüngt sich das Rückenmark zum Conus medullaris und endet als dünner Strang (Filum terminale). Vom Conus medullaris an enthält der Wirbelkanal nur noch eine dichte Masse von abwärts laufenden Nervenfasern (Spinalwurzeln), die man als Cauda equina (Pferdeschwanz) zusammenfasst.

Das Rückenmark wird von zwei Quellen aus mit Blut versorgt: von den Wirbelarterien und von den Segmentarterien [siehe Arterie]. Die Rückenmarksvenen bilden ein Netzwerk, das mit den Nervenwurzeln verläuft und in größere Venen auf der harten Rückenmarks-/Hirnhaut mündet.

Bezug zur Kinderkrebsheilkunde: Bei Kindern liegt das Ende des Rückenmarks ungefähr in Höhe des vierten Lendenwirbels. Unterhalb dieses Bereiches ist es üblich, Lumbalpunktionen 
durchzuführen, da auf dieser Höhe kaum Gefahr besteht, das Rückenmark oder eine Nervenwurzel zu verletzen.

3.3.6.2. Funktion des Rückenmarks: Nachrichtenvermittlung zwischen Gehirn und anderen Körperorganen

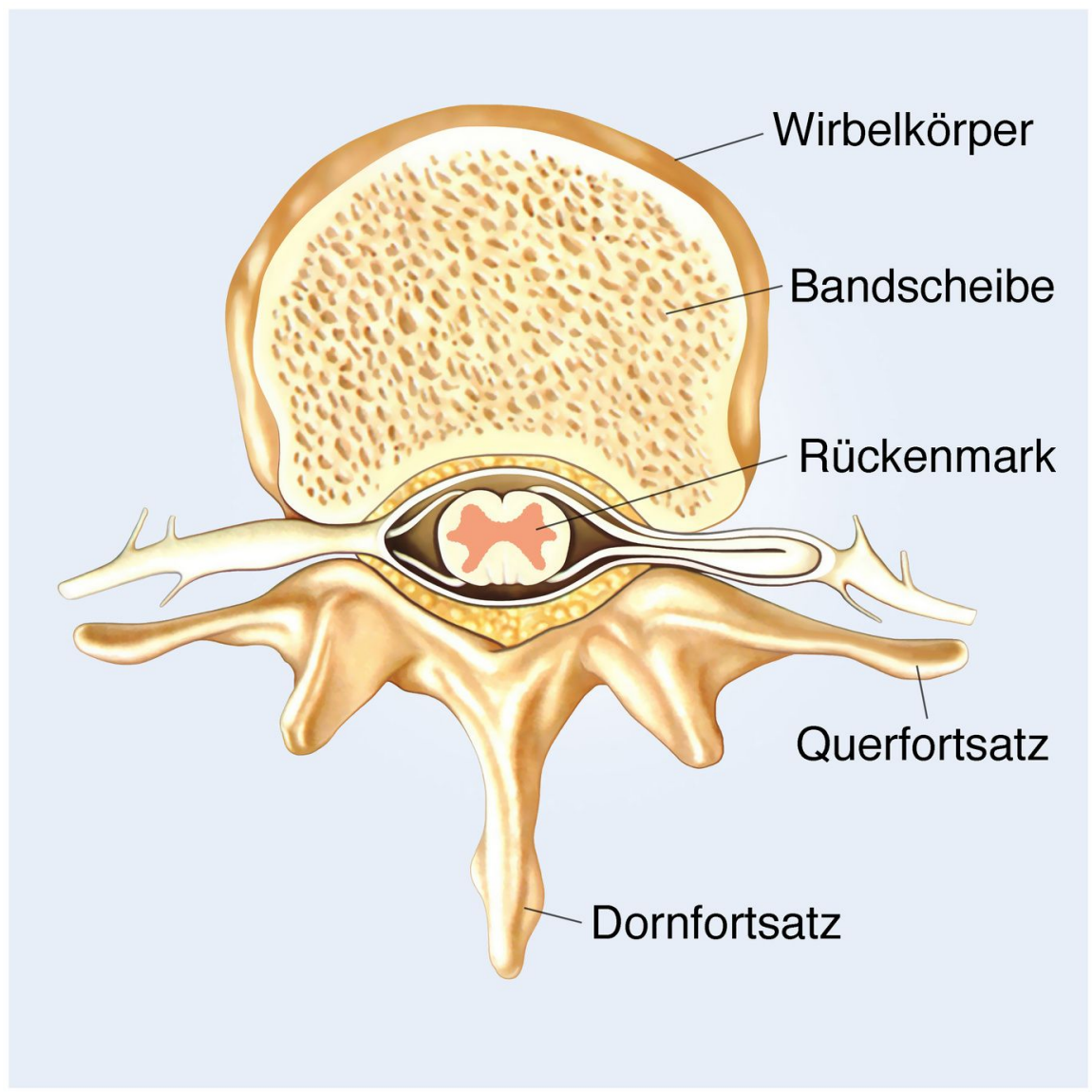

Die Nervenzellkörper (graue Substanz) liegen im Rückenmark innen und ihre Verteilung erinnert an eine Schmetterlingsfigur, die von den Nervenfaserbahnen (weiße Substanz) umgeben ist. 


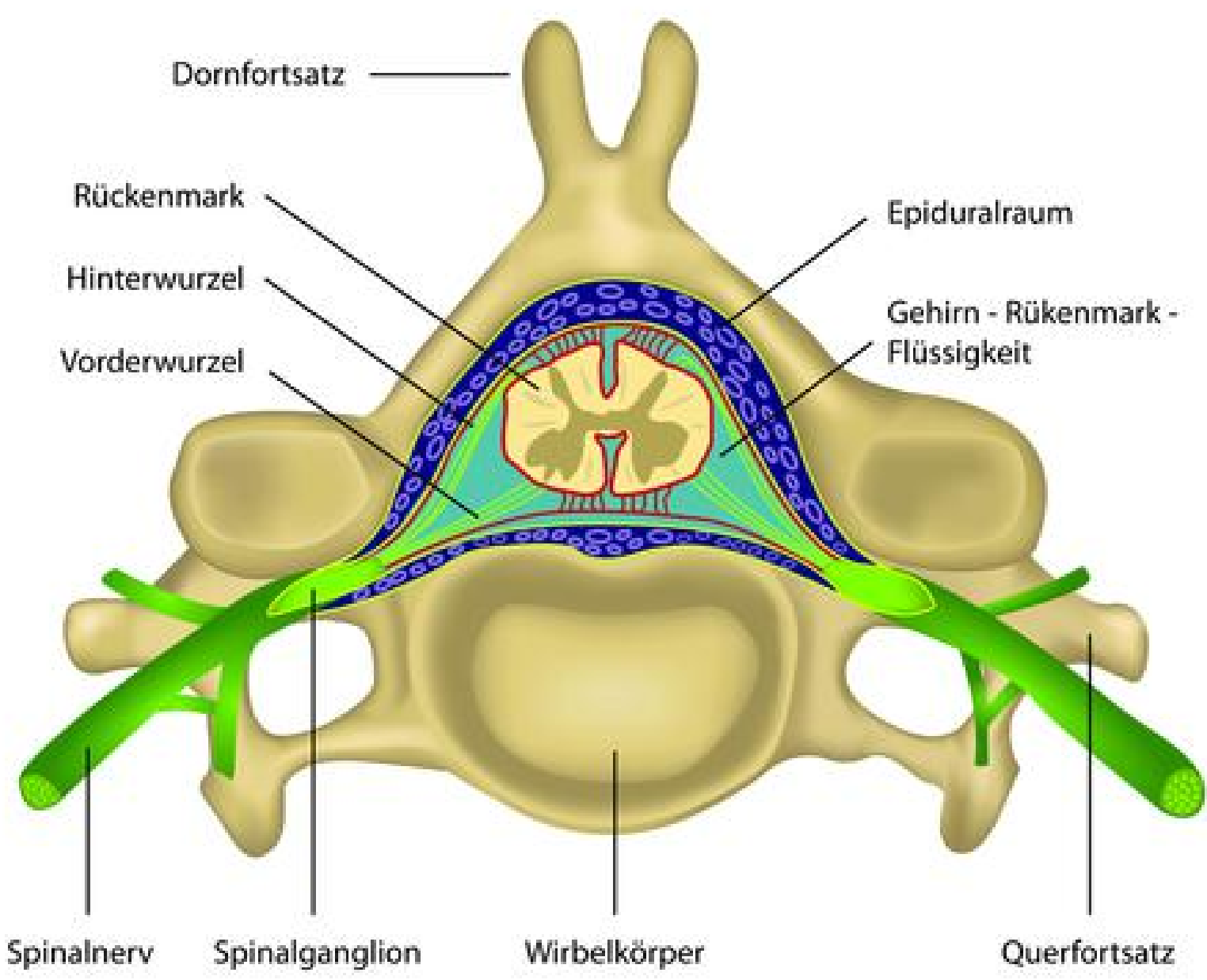

Man unterscheidet in der grauen Substanz:

- das Hinterhorn: Es enthält die Nervenzellkörper, die für die Weiterleitung von Gefühlsempfindungen wie Berührung oder Schmerz aus dem Körperinneren oder aus der Umwelt zum Gehirn verantwortlich sind (sensible Nervenzellen).

- das Vorderhorn: Es enthält die Nervenzellen, die für die Weiterleitung von Befehlen vom Gehirn an die Muskeln verantwortlich sind (motorische Nervenzellen). 
- das Seitenhorn: Es enthält Nervenzellen des autonomen Nervensystems (vegetative Nervenzellen). (autonomes Nervensystem; siehe auch Kapitel "Vegetatives Nervensystem")

\section{Weiße Substanz}

Die weiße Substanz enthält die entsprechend zugehörigen Nervenfaserbahnen. Sie leiten die Erregungen aus dem Körperinneren oder der Umwelt zum Gehirn (afferente Bahnen) oder vom Gehirn zurück zu den Organsystemen (efferente Bahnen) weiter oder aber hemmen diese Nachrichtenübermittlung.

Die größte vom Gehirn durch das Rückenmark absteigende Bahn ist die Pyramidenbahn (siehe auch Kapitel "Funktionelle Systeme"). Im gesunden Rückenmark werden wichtige Signale weitergegeben, unwichtige gehemmt.

\section{Spinalnerven}

An beiden Seiten des Rückenmarks treten Nervenfasern ein und aus, die sich erst zu Nervenwurzeln (Vorder- und Hinterwurzeln) vereinigen und sich im weiteren Verlauf zum Spinalnerv zusammenzuschließen.

Der Spinalnerv enthält alle Fasern, aufsteigende (afferente) wie absteigende (efferente), und geht in Nerven des peripheren Nervensystems über [peripheres Nervensystem]. Diese versorgen dann beispielsweise innere Organe, Haut, Muskeln und Blutgefäße mit Befehlen vom Gehirn oder nehmen deren Nachrichten zur Weiterleitung zum Gehirn entgegen.

Periphere Nerven sind also die "Nachrichtenkanäle", die dem Rückenmark alle Arten von Erregungen aus der Umwelt und aus dem Körperinneren zuführen beziehungsweise die Reizantworten von Rückenmark oder Gehirn wieder in die Umgebung (Peripherie) leiten.

Im Spinalnerv, also kurz vor Eintritt ins / Austritt aus dem Rückenmark, erfolgt die Aufteilung in die Fasern der auf- und absteigenden (afferenten und efferenten) Bahnen. Beim Menschen zählt man in der Regel 31 Spinalnervenpaare, die jeweils seitlich aus dem Wirbelsäulenkanal austreten. Jedes Spinalnervenpaar versorgt ein Körpersegment (Dermatom).

\subsection{Reflexe}

Manche Erregungen (Reize) werden von den aufsteigenden Bahnen im Rückenmark gar nicht erst zum Gehirn weitergeleitet, sondern unmittelbar auf derselben oder einer höher gelegenen Rückenmarksebene umgeschaltet. Die aufsteigenden Fasern verlaufen in diesem Fall statt zum Gehirn direkt zu Zellen des Vorderhorns und übertragen dort die Erregung. Diese wird dann automatisch über die absteigenden Fasern sofort wieder an die Muskelzelle weitergeleitet.

Diesen Weg der Erregungsübertragung nennt man Reflexbogen, und eine so ausgelöste Muskelreaktion nennt man Reflex. Durch Reflexe wird eine schnelle, automatische Reaktion ausgelöst, ohne dass das Gehirn dazu "eingeschaltet" wird, also ohne dass gedacht werden muss.

Reflexe werden bei jeder körperlichen Untersuchung geprüft. Dabei wird zwischen Eigenreflexen und Fremdreflexen unterschieden. 


\section{Eigenreflex}

Bei einem Eigenreflex wird ein Muskel durch einen sachten Schlag auf eine Sehne kurz gedehnt. Durch diese Reizung wird der oben beschriebene Reflexbogen ausgelöst, der die betroffene Rückenmarksebene nicht verlässt. Als Gegenreaktion kommt es zu einer kurzen Muskelanspannung.

Bei der Prüfung der Eigenreflexe wird unter anderem die Stärke dieser Muskelanspannung bewertet. Beispiel für einen Eigenreflex ist der Patellarsehnenreflex (ausgelöst durch einen kurzen Schlag auf die Sehne unterhalb der Kniescheibe, nach dem das Bein dann im Kniegelenk kurz gestreckt wird).

\section{Fremdreflex}

Bei einem Fremdreflex gehören Reizempfänger und Reizbeantworter verschiedenen Organsystemen an. Es werden Sinneszellen in der Haut gereizt und dadurch ein Reflexbogen ausgelöst, der sich über verschiedene Höhen des Rückenmarks (des Hirnstamms) ausbreitet. Die zugehörige Muskelantwort besteht aus einer Fluchtbewegung.

Beispielsweise kommt es beim Babinski-Reflex durch Bestreichen des Fußsohlenrandes zu einer Streckung von Fuß und Großzehe sowie Spreizung der übrigen Zehen im Sinne einer Fluchtreaktion, die den schädigenden Reiz entfernen soll. Dieses Babinski-Phänomen ist normal für Neugeborene und Kinder im ersten Lebensjahr. Bleibt er länger nachweisbar oder tritt bei älteren Kindern neu auf, kann das ein Zeichen für eine Schädigung der Nachrichtenweiterleitung im Rückenmark sein.

Im Allgemeinen deuten abgeschwächte Reflexe auf eine Schädigung im Bereich des peripheren Nervensystems hin [siehe peripheres Nervensystem], gesteigerte Reflexe auf Störungen des Zentralnervensystems. Deshalb bedürfen Auffälligkeiten bei der Reflexprüfung immer weiterer Abklärung.

\subsubsection{Bezug zur Kinderkrebsheilkunde}

Das Rückenmark beziehungsweise die auf- und absteigenden Bahnen im Rückenmark können zum Beispiel durch einen Tumor geschädigt werden, der auf bestimmte Regionen im äußeren (peripheren) Bereich des Rückenmarks drückt oder der sich sogar im Mark, also innerhalb (zentral) dieser Bahnen befindet. Für eine entsprechende Schädigung dieser Bereiche sprechen unter anderem:

- Störungen der Gefühlswahrnehmung bestimmter Körpersegmente (Dermatome; siehe Abschnitt zu Spinalnerven oben);

- Reflexstörungen (siehe Abschnitt zu Reflexen oben)

- Störungen der Körperhaltung

- Gleichgewichtsstörungen 
- Lähmungen von Muskeln. Dabei spricht man von "Parese", wenn noch eine Restbeweglichkeit vorhanden ist und von "Plegie", wenn eine vollständige Lähmung vorliegt, das betroffene Gliedmaß also nicht mehr ohne fremde Hilfe bewegt werden kann.

Im Folgenden erhalten Sie einige Beispiele für verschiedene Lähmungen mit Ursache im Rückenmark (spinale Lähmungen).

\subsection{Zentrale spinale Lähmung}

Werden beispielsweise vermehrt "unwichtige" Erregungen zum Gehirn und entsprechend zu viele und "unwichtige" Befehle an die Muskelzellen weitergeleitet, weil die Hemmung in den auf- und/ oder absteigenden Nervenfaserbahnen des Rückenmarks wegen einer zentral, also im Mark gelegenen Schädigung nicht mehr richtig funktioniert, so ist eine erhöhte Muskelspannung mit Bewegungseinschränkung der Gliedmaßen die Folge.

Dieses Phänomen wird unter anderem für die Entstehung einer spastischen Lähmung verantwortlich gemacht. Eine spastische Lähmung kann ein Zeichen für Schädigungen im Bereich der vom Gehirn durch das Rückenmark absteigenden Bahnen sein.

\subsection{Periphere spinale Lähmung}

Wenn, umgekehrt, in den auf- oder absteigenden Bahnen zu viel gehemmt wird, erhalten die Muskelzellen zu wenige erregende Impulse und es entsteht eine schlaffe Lähmung. Dabei haben die betroffenen Muskeln keine Spannkraft mehr und das zugehörige Gliedmaß hängt schlaff herab.

Eine solche periphere spinale Lähmung entsteht zum Beispiel dann, wenn ein Tumor die Erregungsleitung im Bereich des Vorderhorns, oder weiter außen (peripher), das heißt bereits vor Eintritt in das Rückenmark oder nach Austritt aus dem Rückenmark (im Bereich der Nervenwurzeln oder der Spinalnerven), schädigt.

\subsection{Halbseitenlähmung (inkompletter Querschnitt)}

Eine Halbseitenlähmung entsteht, wenn die Nervenfaserbahnen einer gesamten Rückenmarkshälfte unterbrochen werden.

\subsection{Komplette spinale Querschnittslähmung}

Eine komplette spinale Querschnittslähmung kann zum Beispiel durch einen Tumor im Rückenmark ausgelöst werden, der durch sein Ausmaß den Querschnitt eines gesamten Rückenmarksabschnittes schädigt, so dass alle auf- und absteigenden Bahnen unterbrochen werden. So kommt es für beide Körperhälften einerseits zum Ausfall von Gefühlsempfindungen, andererseits können keine Befehle mehr an die Muskeln weitergeleitet werden.

Das Ausmaß dieser Querschnittslähmung ist einerseits abhängig davon, auf welcher Höhe des Rückenmarks sich der Tumor befindet (hohes oder unteres Halsmark, Brustmark, unterer Abschnitt des Rückenmarks), und andererseits davon, wie viel des Querschnittes er einnimmt.

Entsprechend kann eine Schädigung im hohen Halsmark, das heißt in Höhe des ersten bis vierten Halswirbelkörpers, die Erregungsleitung von und zu allen darunter liegenden Körpersegmenten wie Zwerchfell, Armen, Beinen, Blase und Mastdarm unterbrechen. Dies führt zu Atemlähmung, Lähmungen und Gefühlsausfällen aller vier Gliedmaßen und der Blasen- und Mastdarmfunktion 
führt. Spinale Querschnittsläsionen führen oft unmittelbar erst zu schlaffen Muskellähmungen, die später in spastische Lähmungen übergehen.

Anmerkung: Die Funktion mancher dieser auf- und absteigenden Bahnen wird im Rahmen der Diagnostik bei Kindern und Jugendlichen mit ZNS-Tumoren mittels elektrophysiologischer Untersuchungen überprüft, beispielsweise durch die Messung von sensibel-evozierten Potentialen [siehe evozierte Potentiale].

\subsubsection{Lagebeschreibungen von Rückenmarksstrukturen und von Tumoren im Rückenmark}

Entscheidend für die Behandlungsplanung und Prognose für Patienten mit ZNS-Tumoren im Bereich des Rückenmarks ist die genaue Lage des Tumors im Rückenmarkskanal. Das Behandlungsteam unterscheidet die folgenden Lokalisationen:

- intraspinal: innerhalb des Rückenmarkskanals

- intraspinal-extramedullär: innerhalb des Rückenmarkskanals, jedoch außerhalb des Rückenmarks gelegen

- intraspinal-intramedullär: innerhalb des Rückenmarkskanals und im Rückenmark gelegen; Tumoren in diesem Bereich sind oft nicht (komplett) entfernbar, und sie sind auch sehr schwierig oder manchmal sogar unmöglich zu bestrahlen, da durch diese Therapiemaßnahmen das Risiko einer schwerwiegenden Rückenmarksverletzung (zum Beispiel eine Querschnittslähmung) besteht.

Bezogen auf die Lage zur harten Hirnhaut (Dura mater) beschreibt man zusätzlich:

- intradural: der harten Hirnhaut ansitzend oder sie durchwachsend. Bei Kindern und Jugendlichen mit Neurofibromatose Typ 1 (NF1) treten typischerweise intraspinale und intradural-extramedullär gelegene Tumoren (Neurofibrome) auf.

- extradural: von Gewebe ausgehend, das die harte Hirnhaut außen umgibt, also beispielsweise von der Wirbelsäule ausgehend. Extradurale primäre Rückenmarkstumoren sind bei Kindern und Jugendlichen eher selten. Jedoch finden sich extradurale Neubildungen in dieser Altersgruppe bei Patienten mit einer Leukämie oder einem Lymphom mit ZNS-Beteiligung. Auch Knochentumoren wie das Osteosarkom oder Keimzelltumoren (wie das Teratom) können intraspinal-extradural-extramedullär wachsen.

\subsubsection{Das Gefäßsystem}

Insbesondere vor der Entfernung von stark durchbluteten Tumoren werden oft Gefäßdarstellungen durchgeführt. Dieser Abschnitt soll helfen, sich besser vorstellen zu können, wie Gehirn und Rückenmark mit Blut versorgt werden und worauf besonders die Operateure und Strahlentherapeuten bei der Therapieplanung achten, damit diese Gefäßversorgung unverletzt bleibt. 
Die Blutversorgung des Gehirns wird von Arterien und Venen vorgenommen.

\subsubsection{Arterien}

Das Gehirn wird von vier großen Arterien versorgt: den zwei inneren Kopfschlagadern (Arteriae carotides internae oder innere Karotiden) und den beiden Wirbelkanalarterien (Arteriae vertebrales). Diese Gefäße geben nach Eintritt in die Schädelgrube zahlreiche Äste ab, die zusammen einen geschlossenen Arterienring (Circulus arteriosus Willisii) an der Unterseite des Gehirns (Hirnbasis) bilden. Dieser enthält Verknüpfungen fast aller Hauptarterien innerhalb der Schädelhöhle, die wiederum verschiedene Äste abgeben und fest zugeordnete Versorgungsgebiete im Gehirn haben.

\subsubsection{Venen}

Die größten Venen liegen an der Oberfläche des Gehirns innerhalb der Hirnhäute, genauer gesagt, im Bereich der Spinngewebshaut (Arachnoidea). Die Hirnvenen fasst man in zwei Gruppen zusammen:

Oberflächliche Hirnvenen (Venae cerebri superiores): Hierbei handelt es sich um circa 10 bis 15 Venen, die das Blut aus allen Großhirnlappen sammeln und es in die großen Venenleiter an der Gehirnoberfläche (die auch Sinus genannt werden) ableiten (siehe auch Kapitel "Großhirn").

Tiefe Hirnvenen (Venae profundae): Diese sammeln unter anderem das Blut aus dem VeneZwischenhirn, aus den tief liegenden Strukturen der beiden Großhirnhälften (Hemisphären) und aus der weißen Substanz des Großhirns. Die tiefen Hirnvenen entleeren ihr Blut in die große Hirnvene (Vena cerebri magna oder Vena Galeni).

\subsection{Bezug zur Kinderkrebsheilkunde}

Abhängig von ihrer Lage können auch Hirntumoren auch den venösen Abfluss im Gehirn blockieren, so dass es in den betroffenen Gebieten zu Blutstauungen und Blutungen kommen kann. Diese können die ihrerseits zu einer Erhöhung des Drucks in der Schädelhöhle mit den entsprechenden Folgen führen.

Bestimmte Substanzen, die bei der Behandlung von Kindern und Jugendlichen mit Krebserkrankungen erfolgreich angewandt werden, wie beispielsweise das Zytostatikum Asparaginase, bergen das Risiko der Entstehung von Blutgerinnseln, die unter anderem zu plötzlichen Verschlüssen von Hirnvenenleitern führen können (Sinusvenenthrombose). Diese Komplikation ist ein Notfall und muss umgehend intensivmedizinisch behandelt werden.

\subsubsection{Das Liquorsystem}

Das Zentralnervensystem (ZNS) ist zu allen Seiten von einer Flüssigkeit, der Gehirn-RückenmarkFlüssigkeit (auch Nervenwasser, Liquor) umgeben. Auch die inneren Hohlräume des Gehirns, die Hirnkammern oder Hirnventrike/), sind mit diesem Liquor gefültt. 
Die Flüssigkeit wirkt wie ein Puffer, der Gehirn und Rückenmark gegen plötzliche Stöße und andere schädliche Einwirkungen schützt. Darüber hinaus hat die Flüssigkeit auch eine nährende Funktion. Sie transportiert Nährstoffe vom Blut zum Nervengewebe und leitet Stoffwechselprodukte ab.

Hirntumoren können je nach ihrer Lage den normalen Fluss der Gehirn-Rückenmark-Flüssigkeit behindern, so dass es zum lebensgefährlichen Aufstau dieser Flüssigkeit kommt. Dadurch können zusätzliche Maßnahmen, zum Beispiel eine Shunt-Operation, notwendig werden. Im Folgenden wird erklärt, wie der Liquor normalerweise fließt, welche Aufgaben er hat und wo genau es durch einen Tumor zu Problemen kommen kann.

\subsubsection{Aufbau und Funktion des Liquorsystems}

Die Gehirn-Rückenmark-Flüssigkeit umgibt Gehirn und Rückenmark und findet sich auch in inneren Hohlräumen des Gehirns. Entsprechend werden innere und äußere Liquorräume unterschieden.

\subsection{Innere Liquorräume}

Das Ventrikelsystem des Gehirns besteht aus vier Hirnkammern Hirnventrike/n:

- den beiden Seitenventrikeln der Großhirnhälften (I. und II. Ventrikel)

- dem Ventrikel des Zwischenhirns (III. Ventrikel)

- dem Ventrikel von Brücke und verlängertem Mark im Hirnstamm (IV. Ventrikel).

Die beiden Seitenventrikel sind durch eine auf jeder Seite gelegenen Öffnung, dem Foramen Monroi, miteinander verbunden. Der III. Ventrikel steht wiederum durch einen Engpass, den Aquäductus cerebri, mit dem IV. Ventrikel in Verbindung.

\subsubsection{2. Äußere Liquorräume}

Gehirn und Rückenmark sind in drei bindegewebige Hirnhäute beziehungsweise Rückenmarkshäute, die Meningen, eingehüllt:

- die harte Hirn-/Rückenmarkshaut (Dura mater): sie grenzt als äußerste Schicht an den Schädelbeziehungsweise Wirbelknochen an.

- die Spinngewebshaut (Arachnoidea): die mittlere Hirnhaut

- die weiche Hirn-/Rückenmarkshaut (Pia mater): Sie legt sich als innerste Schicht direkt an die Oberfläche von Gehirn bzw. Rückenmark an. 
Der äußere Liquorraum befindet sich zwischen der Spinngewebshaut (Arachnoidea) und der weichen Hirn- / Rückenmarkshaut (Pia mater). Der Spalt zwischen diesen beiden weichen inneren Hirnhäuten ist mit Gehirn-Rückenmark-Flüssigkeit gefüllt und wird auch als Subarachnoidalraum bezeichnet.

\subsubsection{Liquorzirkulation}

Die Gehirn-Rückenmark-Flüssigkeit wird in speziellen Knäueln aus kleinen Arterien und Venen, dem Plexus choroideus, von bestimmten Ependymzellen gebildet, welche die Wände der Liquorräume auskleiden (siehe auch Kapitel "Feingeweblicher Aufbau"). Dies erfolgt in allen Liquorräumen mit Ausnahme des vorderen und hinteren Anteils der Seitenventrikel und des Aquäductus cerebri (siehe oben).

Der Liquor fließt von den beiden Seitenventrikeln (I. und II. Hirnventrikel) in den III. Ventrikel und von diesem durch das Aquäduct in den IV. Ventrikel. Von hier aus gelangt er über kleine Öffnungen in den äußeren Liquorraum, wo er über kleine Venen in die Lymphbahn abgeleitet und abgebaut wird.

\subsubsection{Bezug zur Kinderkrebsheilkunde:}

Bei Kindern und Jugendlichen kommen Tumoren vor, die aus entarteten Ependymzellen, hervorgehen. Diese Tumoren, die Ependymome, können überall im Bereich der Liquorräume, das heißt in den Hohlräumen des Gehirns und des Rückenmarks entstehen. Manche dieser Tumoren können selbständig Liquor produzieren und dadurch zum Wasserkopf (Hydrocephalus) führen.

Ein Tumor im Kleinhirn (zum Beispiel ein Medulloblastom oder Astrozytom) wiederum kann zum Beispiel von hinten den IV. Hirnventrike/ verschließen und dadurch zum Liquoraufstau in den beiden Seitenventrikeln (I. und II. Ventrikel) und dem III. Ventrikel führen (innerer Verschlusshydrocephalus oder Hydrocephalus internus occlusus).

Ein solcher Verschlusshydrocephalus kann vorübergehend sein oder aber (durch narbige Verwachsungen nach einer Tumorentfernung oder Bestrahlung) dauerhaft bestehen bleiben. Auf jeden Fall führt er unbehandelt und in Abhängigkeit von der Geschwindigkeit des Tumorwachstums früher oder später zu einer lebensgefährlichen Druckerhöhung in der Schädelhöhle.

Neben der Tumorentfernung werden dann zusätzliche neurochirurgische Maßnahmen notwendig, wie die Anlage einer externen Ventrikeldrainage [siehe externe Ventrikeldrainage], eines ventrikuloperitonealen Shunts [siehe ventrikulo-peritonealer Shunt] oder einer Ventrikulostomie.

Diese Eingriffe werden in den Texten zu den verschiedenen ZNS-Tumoren innerhalb des Kapitels "Supportivtherapie" (unter Behandlungsmethoden) noch weiter erläutert.

\subsubsection{Das vegetative Nervensystem}

Da eine der Aufgaben des Zentralnervensystems (ZNS) die Regulation des vegetativen Nervensystems ist, soll hier kurz erklärt werden, wie dieses die Funktionen der menschlichen Körperorgane aufrechterhält, kontrolliert und steuert. 


\subsubsection{Aufbau und Funktion des vegetativen Nervensystems}

Das vegetative (oder viszerale oder autonome) Nervensystem ist für die Versorgung der inneren Organe (Eingeweide, Blutgefäße, Drüsen) zuständig. Dazu sind beinahe alle Körpergewebe von einem feinen Nervenfasergeflecht durchsetzt.

Wie beim Zentralnervensystem (ZNS) unterscheidet man auch beim vegetativen Nervensystem jene Nervenbahnen, die von den inneren Organen zum Gehirn aufsteigen, um Informationen abzugeben (afferente, sensible Nervenbahnen) und solche, die vom Gehirn durch das Rückenmark zur Organmuskulatur und zu den Drüsen absteigen und Befehle abgeben (efferente, motorische und sekretorische Nervenbahnen).

Die Hauptaufgabe des vegetativen Nervensystems besteht darin, das innere Milieu des Organismus, das heißt, die lebenswichtigen Funktionen (Vitalfunktionen) - wie zum Beispiel Stoffwechsel, Atmung, Kreislauf und Wasserhaushalt - aufrechtzuerhalten. Außerdem reguliert das vegetative Nervensystem verschiedene Organfunktionen, auch die von Drüsen, Geschlechtsorganen und einigen Augenmuskeln, und sorgt damit für deren Anpassung an die wechselnden Umwelterfordernisse.

Die oberste Kontrollinstanz des vegetativen Nervensystems ist der Hypothalamus im Zwischenhirn (siehe auch Kapitel "Zwischenhirn"). Durch seine Zusammenarbeit mit der Hirnanhangsdrüse (Hypophyse) reguliert er vor allem die Tätigkeit der Hormon-produzierenden Drüsen. Außerdem ist an der zentralen Regulation von Herzschlag, Atmung und Blutdruck zusätzlich eine Struktur im Hirnstamm (Formatio reticularis) beteiligt.

Das vegetative Nervensytem kann nicht willkürlich beeinflusst werden. Es steuert sich selbst, funktioniert also autonom. Aus diesem Grund wird es auch autonomes Nervensystem genannt.

Im Hinblick auf seine strukturellen und funktionellen Eigenschaften kann das vegetative Nervensystem in zwei Teile gegliedert werden: Sympathicus [sympathisches Nervensystem] und Parasympathicus [parasympathisches Nervensystem]. Die beiden Systeme wirken einander entgegen und regulieren sich dadurch selbst. Auf diese Weise wird im gesunden menschlichen Organismus ein lebensnotwendiges Gleichgewicht der Organfunktionen aufrechterhalten. Bis auf wenige Ausnahmen wird die Funktion aller inneren Organe von beiden Anteilen des vegetativen Nervensystems gesteuert.

Sympathisches und parasympathisches Nervensystem haben Anteile sowohl im Zentralnervensystem als auch im peripheren Nervensystem: Zum zentralen (vegetativen) Nervensystem gehören die im ZNS gelegenen Zellgruppen von Sympathicus und Parasympathicus. Parasympathische Nervenzellkerngruppen liegen im Hirnstamm und auch im Rückenmark im Steißbeinbereich, während die meisten sympathischen Nervenzellkerne im Rückenmark von Brust- und Lendenwirbelsäule anzutreffen sind (siehe auch Abbildung zum autonomen Nervensystem im Seitenteaser rechts).

\subsubsection{Sympathisches Nervensystem (Sympathicus)}

Der Sympathicus wird durch erhöhte körperliche Leistung erregt, er hat eine energiemobilisierende und aktivitätssteigernde Funktion für den Körper. Der Symphaticus bewirkt eine Erhöhung des 
Blutdrucks, eine Beschleunigung von Herzschlag und Atmung, eine Erweiterung der Pupillen und, zum Beispiel, eine vermehrte Schweißabsonderung. Gleichzeitig dämpft er die Tätigkeiten von Magen und Darm (Herabsetzung der Peristaltik) sowie deren Drüsen.

Die Zellkörper der sympathischen Nervenzellen liegen hauptsächlich im Rückenmark von Brustund Lendenwirbelsäule. Von dort schicken sie ihre Fasern zum sympathischen Grenzstrang (Truncus sympathicus). Es handelt sich dabei um eine Kette von Nervenzellhaufen (sympathischen Ganglien), die zu beiden Seiten der Wirbelsäule von der Schädelbasis bis zum Steißbein verläuft. Vom Grenzstrang aus ziehen dann Nervenfasern zu den einzelnen Organen, wo sie sich netzartig ausbreiten (siehe Abbildung unten).

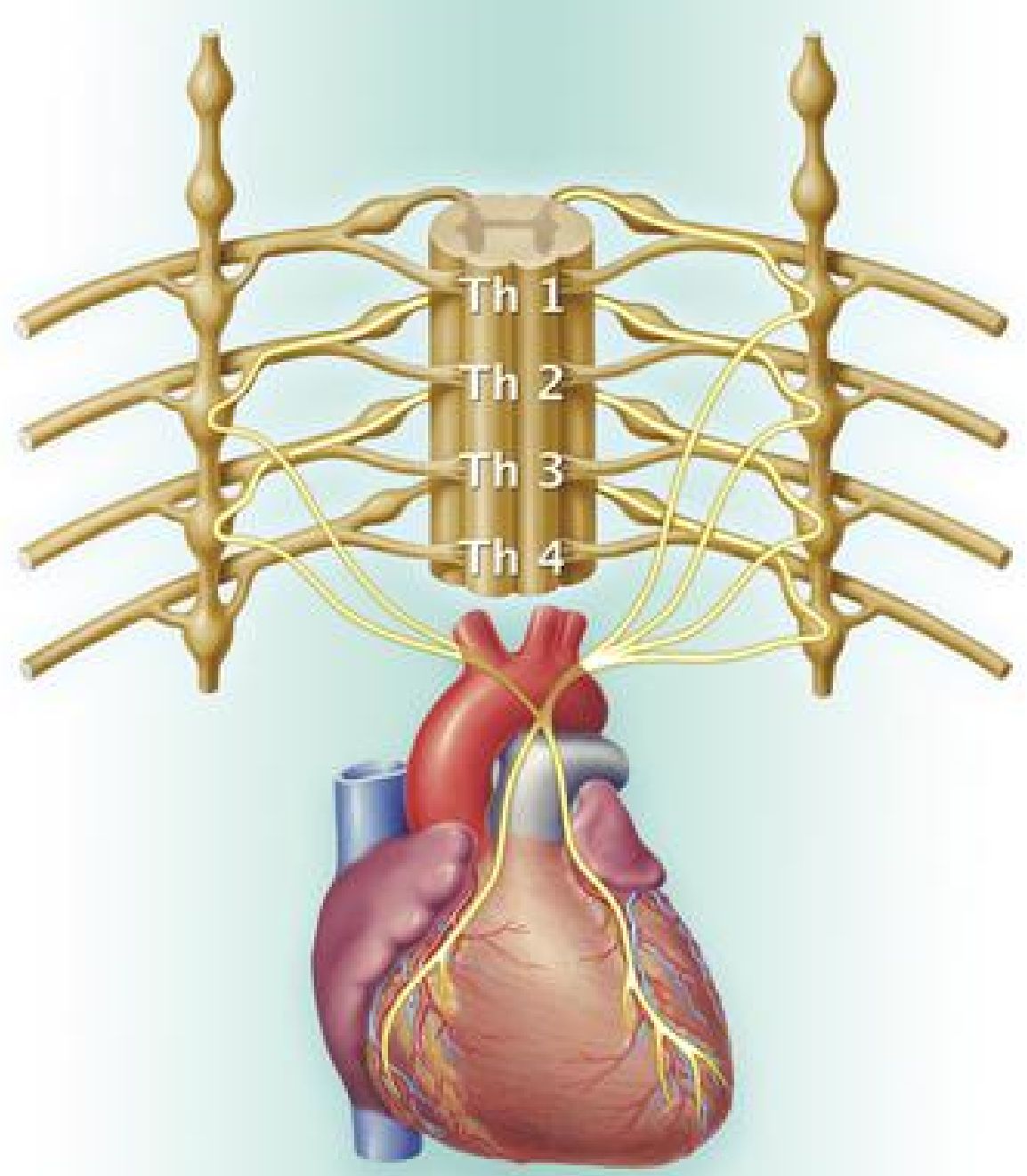


Die Erregungsübertragung erfolgt im Sympathicus durch die chemische Substanz (Neurotransmitter) Noradrenalin (siehe Kapitel "Feingeweblicher Aufbau", Abschnitt zur Nervenzelle).

\subsubsection{Parasympathisches Nervensystem (Parasympathicus)}

Der Parasympathicus sorgt, im Gegensatz zum Sympathicus, eher für den Erhalt und den Wiederaufbau der Körperenergien. Überwiegt der Einfluss des Parasympathicus, so kommt es einerseits zum Beispiel zur Verlangsamung von Herzschlag und Atmung und zur Pupillenverengung; andererseits werden Magen-Darm-Tätigkeit verstärkt und die Blasen- und Mastdarmfunktion gefördert.

Der Hauptnerv des Parasympathicus ist der X. Hirnnerv (Nervus vagus). Dieser entspringt im verlängerten Mark des Hirnstamms, also im Gehirn, zieht von dort aus, zusammen mit den großen Halsgefäßen, abwärts und breitet sich in Höhe des Brustkorbs netzartig im Bereich der Brust- und Bauchorgane aus. Aber auch andere Hirnnerven, beispielsweise der III. Hirnnerv (Augenmuskelnerv), führen parasympathische Fasern (siehe dazu auch Kapitel "Hirnstamm und Hirnnerven"). Weitere Nervenzellgruppen des Parasympathicus liegen im Rückenmark im Steißbeinbereich.

Die Erregungsübertragung erfolgt im Parasympathicus durch den Neurotransmitter Acetylcholin (siehe Kapitel "Feingeweblicher Aufbau", Abschnitt zur Nervenzelle).

Der Sympathicus dient also der Leistungssteigerung, zum Beispiel in Stress- und Notfallsituationen, während der Parasympathicus hauptsächlich für die Erholung und den Aufbau körperlicher Reserven verantwortlich ist.

\subsubsection{Bezug zur Kinderkrebsheilkunde:}

Ein Tumor des Zentralnervensystems befällt selten das vegetative Nervensystem allein. Durch den von einem ZNS-Tumor ausgehenden Druck kann es jedoch zu Funktionsausfällen kommen, die den zentralen Anteil des vegetativen Nervensystems (zum Beispiel dessen Nervenzellkerngruppen im Hirnstamm) miteinbeziehen, was wiederum Störungen für die Endorgane mit sich bringen kann.

Andere bösartige Neubildungen wie die Neuroblastome können hingegen von entarteten, unreifen Zellen des sympathischen Grenzstrangs ausgehen.

\subsubsection{Funktionelle Systeme (Nachrichtensysteme)}

Dieser Abschnitt beschäftigt sich vor allem mit den Nervenbahnen in Gehirn und Rückenmark, welche für die Kontrolle und Regulierung der "gewollten", "bewussten" und "beabsichtigten" (willkürlichen) Bewegungen verantwortlich sind (siehe Pyramidenbahn und extrapyramidal-motorisches System).

Über diese Nervenbahnen kontrolliert die Großhirnrinde alle unter ihr befindlichen (motorischen) Zentren, die für willkürliche Muskelbewegungen zuständig sind (siehe auch Kapitel "Großhirn"). Die 
Großhirnrinde kann einerseits dämpfend und hemmend auf diese Zentren wirken, andererseits aber auch ständige Muskelspannung auslösen, die vor allem rasche, plötzliche Bewegungen fördert.

Im Anschluss werden noch kurz andere Systeme zur Vermittlung von verschiedenen Nachrichtentypen angesprochen.

\subsubsection{Pyramidenbahn}

Die Nervenfasern der Pyramidenbahn entspringen in einem Großhirnrindengebiet des Vorderlappens und in Rindenfeldern des Scheitellappens (siehe Kapitel "Großhirn"). Sie ziehen bis zum Rückenmark, wo manche von ihnen auf die Gegenseite übertreten (deshalb ist bei einseitigen Schädigungen die Gegenseite gelähmt) und von dort abwärts ziehen.

Impulse der Pyramidenbahn aktivieren alle Nervenzellen, die Beugemuskeln versorgen und hemmen alle Nervenzellen, die Streckmuskeln versorgen. Dadurch wird vor allem die Feinabstimmung von automatischen Bewegungsabläufen (zum Beispiel Laufen, Greifen) gefördert.

\subsection{Bezug zur Kinderkrebsheilkunde}

Eine Schädigung der Pyramidenbahn kann zu Lähmungen und Störungen bei der Durchführung feiner Bewegungsabläufe (zum Beispiel Faden einfädeln, schreiben) führen.

\subsubsection{Extrapyramidal-motorisches System}

Zum extrapyramidal-motorischen System gehören alle für Muskelbewegungen zuständigen Nervenbahnen, die durch das Rückenmark ziehen und nicht der Pyramidenbahn angehören.

Die Ursprungsorte dieser Nervenbahnen, die neben der Pyramidenbahn die Motorik beeinflussen, liegen insbesondere in den Nervenzellkernen tief in der weißen Substanz des Großhirns (siehe Kapitel "Großhirn", Abschnitt zu Basalganglien). Diese stehen mit dem Kleinhirn, dem Thalamus im Zwischenhirn und dem Hirnstamm in Verbindung.

Bei einer "gewollten" (willkürlichen) Bewegung werden, zusätzlich zu den Muskeln, die diese Bewegung ausführen, Muskelgruppen an anderen Gliedmaßen und am Rumpf aktiv, damit bei den sich ändernden Haltungsbedingungen das Gleichgewicht und die Körperhaltung aufrechterhalten werden und die Bewegung glatt abläuft.

Solche eher unbewusst ausgeführten Bewegungsabläufe sind beispielsweise das Armpendeln beim Gehen und viele andere, lange eingeübte und mechanisch ablaufende Bewegungen. Sie alle stehen unter der Kontrolle des extrapyramidal-motorischen Systems, das selbständig alle willkürlichen Bewegungen unterstützt.

\subsection{Bezug zur Kinderkrebsheilkunde}

Bei einer Schädigung des extrapyramidal-motorischen Systems kann es beispielsweise zu Störungen der Muskelspannung kommen, die sich in unwillkürlich auftretenden Muskelanspannungen äußern (Dystonie), außerdem auch zu gesteigerten Muskelbewegungen, 
beispielsweise zu plötzlichen, unvorhersehbaren, unkontrollierten Bewegungen von Armen oder Beinen (Hyperkinese).

\subsubsection{Bahnen für Gefühlsempfindungen}

Weitere Nachrichtensysteme des Nervensystems bestehen aus den Nervenfaserbahnen, die für die Weiterleitung und Verarbeitung von Gefühlsempfindungen (Sensibilität) verantwortlich sind, wie Berührung, Vibration, Stellung der Gelenke sowie Schmerz und Temperatur. Die Informationen stammen jeweils aus den sensiblen Fasern der Nerven des peripheren Nervensystems [siehe peripheres Nervensystem], gelangen dann in die Rückenmarksbahnen und ziehen in diesen zu ihrem Endigungsgebiet im Zwischenhirn, genauer im Thalamus (siehe Kapitel "Zwischenhirn").

\subsubsection{Bahnen für den Geschmack}

Die verschiedenen Geschmackserlebnisse werden von Zellgruppen auf der Zunge wahrgenommen, die Geschmacksknospen oder auch Chemorezeptoren genannt werden. Diese nehmen in unterschiedlicher Weise die Geschmacksqualitäten "süß", "sauer", "bitter" und "salzig" wahr, welche sie dann über kleine Nervenfasern in drei verschiedenen Hirnnerven (dem V., X. und XI. Hirnnerv; siehe Kapitel "Hirnstamm und Hirnnerven") durch den Hirnstamm ins Zwischenhirn (zu Thalamus und Hypothalamus) weiterleiten.

Von dort aus werden die Informationen zu ihrer endgültigen Verarbeitung geschickt: einerseits zu einem bestimmten Bereich der Großhirnrinde (Rindenfeld im Scheitellappen) für die Bildung überlegter Reaktionen (siehe Kapitel "Großhirn"); andererseits werden zur unmittelbaren Reizbeantwortung direkt vom Zwischenhirn vegetative Reaktionen wie Speichelbildung und die Ausschüttung von Magensaft ausgelöst.

\subsubsection{Bahnen für den Geruchssinn}

Geruchserlebnisse werden über Riechzellen (Riechepithel) wahrgenommen. Darunter versteht man Sinneszellgruppen in der Schleimhaut der oberen Nasenmuschel und der Nasenscheidewand. Die Zellen haben jeweils einen kleinen Stiel (Riechkegel) mit einem dünnen Fortsatz, der mit den Fortsätzen anderer Riechzellen beidseits zum II. Hirnnerv (siehe Kapitel "Hirnstamm und Hirnnerven") gebündelt wird und zum Riechzentrum im Großhirn zieht.

\subsubsection{Limbisches System}

Die, bezogen auf die Entwicklungsgeschichte des Großhirns, ältesten Anteile der beiden Großhirnhälften werden mit ihren Randgebieten und Verbindungen zu Zentren, die sich unterhalb der Großhirnrinde befinden, als limbisches System zusammengefasst.

Das limbische System wird auch als "emotionales" Gehirn bezeichnet, weil es an vielen emotionalen und auch triebhaften Hirnleistungen (unter anderem Angst, Freude, Wut) beteiligt ist. Es ist auch durch verschiedene Nervenfaserbündel mit dem Riechzentrum, mit dem Zwischenhirn und dadurch mit dem vegetativen Nervensystem verknüpft (vegetatives Nervensystem; siehe auch Kapitel "Vegetatives Nervensystem"). 
Zum limbischen System gehören beispielsweise eine spezielle bogenförmige Hirnwindung, der Gyrus cinguli, die Hippocampusformation im Großhirn und die daneben liegende Windung (Gyrus parahippocampalis) sowie andere Nervenzellkerngebiete im Großhirn und im Zwischenhirn. Da das limbische System eher auf funktionellen Zusammenhängen als auf anatomischen Strukturen beruht, sind die dazu gehörenden Hirnanteile nur ungenau definiert.

\subsection{Bezug zur Kinderkrebsheilkunde}

Die Funktionen des limbischen Systems können durchaus durch einen Tumor, eine Operation oder auch eine Strahlentherapie in bestimmten Hirnregionen beeinflusst werden. 


\section{Literaturverzeichnis}




\section{Glossar}

Acetylcholin

Arterie

Astrozyten

Astrozytom

Ataxie

autonomes Nervensystem

Basalganglien einer der wichtigsten Neurotransmitter beim Menschen, vermittelt z.B. die Erregungsübertragung zwischen Nerv und Muskel

pulsierendes Blutgefäß, das Blut vom Herzen wegführt; Arterien des so genannten großen Körperkreislaufs transportieren sauerstoffreiches, helles Blut vom Herzen zu den zu versorgenden Organen. Die Arterien des Lungenkreislaufs (oder kleinen Kreislaufs) führen sauerstoffarmes Blut vom Herzen der Lunge zu, wo es wieder mit Sauerstoff beladen wird. Die größte Arterie beim Menschen ist die Hauptschlagader (Aorta).

Hauptform der Gliazellen im Zentralnervensystem; benannt nach ihrem stern- bzw. spinnenförmigen Aufbau (von griech. astron = Stern). Die Fortsätze dieser Zellen bilden Grenzmembranen zur Gehirnoberfläche (bzw. Pia mater) und zu den Blutgefäßen.

von Astrozyten (einer Unterform der Gliazellen) abstammender Tumor des Zentralnervensystems; gehört zu den so genannten Gliomen

Störung der Koordination von Bewegungsabläufen, z.B. durch ein nicht (mehr) exakt funktionierendes Zusammenspiel verschiedener Muskelgruppen zur Durchführung einer bestimmten Bewegung (Asynergie) oder durch falsche Abmessung von Zielbewegungen (Dysmetrie)

Teil des Nervensystems; setzt sich aus zwei Anteilen, dem Sympathicus und dem Parasymphaticus, zusammen und dient der unbewussten und unwillkürlichen (d.h. der vom Willen weitgehend unabhängigen) Steuerung der inneren Organe und damit zahlreicher lebenswichtiger Vorgänge, zum Beispiel Atmung, Verdauung, Blutdruckregulation, und Wasserhaushalt. Nervenfasern des vegetativen Nervensystems gibt es in fast allen Körperorganen.

Gruppen von Nervenzellkernen (graue Substanz), die in der Tiefe der weißen Substanz der beiden Großhirnhemisphären liegen. Sie sind für bestimmte Muskelaktivitäten (extrapyramidal-motorisches System) zuständig, die für die Steuerung der Grobmotorik von Bedeutung sind. Im Zusammenspiel mit dem Kleinhirn, welches für die Feinmotorik steuert, sind die Basalganglien an der Planung von Bewegung beteiligt. 
Bestrahlung

bildgebende Verfahren

Blut-Hirn-Schranke

Brücke

Diabetes insipidus

Diagnostik

Differenzierung

Dopamin

Dysmetrie

Embryonalentwicklung kontrollierte Anwendung ionisierender Strahlen zur Behandlung von bösartigen Erkrankungen

Untersuchungsmethoden, die Bilder vom Körperinneren erzeugen; hierzu zählen z.B. die Ultraschall- und Röntgenuntersuchung, Computertomographie, Magnetresonanztomographie und Szintigraphie.

Schranke zwischen Blut und Zentralnervensystem (ZNS), die nur für bestimmte körpereigene und -fremde Stoffe durchlässig ist und dadurch eine aktive Kontrolle über den Stoffaustausch mit dem ZNS ermöglicht. (Besteht vermutlich aus speziellen Zellen in den Wänden und der Umgebung der Hirngefäße.)

Teil des Hirnstamms, der zwischen Mittelhirn und verlängertem Mark liegt und nach hinten durch das Kleinhirn begrenzt wird. Die Brücke enthält u.a. die Ursprungsorte für den V. bis VIII. Hirnnerv sowie Teile des Atem-, Kreislauf- und Aktivitätszentrums.

Starke Steigerung der Urinausscheidung mit Harnmengen von mehreren Litern pro Tag. Ursache ist i.d.R. eine Störung im Hinterlappen der Hirnanhangsdrüse (Hypophyse) oder eines übergeordneten Hirnzentrums und dadurch verursachter fehlender Wirkung des antidiuretischen Hormons (ADH).

Methoden/Maßnahmen zur Erkennung eines Krankheitsgeschehens

hier: Entwicklung von unreifen Zellen / unreifem Gewebe zu reifen Strukturen mit spezialisierten Aufgaben. Die Differenzierung erfolgt nach einem erblichen Bauplan.

Vorstufe der körpereigenen Katecholamine Noradrenalin und Adrenalin und Botenstoff bei der Weiterleitung von Nervenerregungen

Störung von Bewegungsabläufen durch falsche Abmessung gezielter Bewegungen; Bewegungen schießen dadurch entweder über das Ziel hinaus oder werden zu kurz angesetzt (Danebengreifen).

Die Embryonalentwicklung i. e. S. bezeichnet die Entwicklungsphase des Embryos zum Zeitpunkt der Organentwicklung (etwa dritte bis Ende der achten Entwicklungsswoche). Im weiteren Sinne kann die Embryogenese für die gesamte Phase der Keimentwicklung vom Zeitpunkt der 
Ependymom

Ependymzellen

Epilepsie

externe Ventrikeldrainage

Gehirn

Gehirn-Rückenmark-

Flüssigkeit

Gliom

Glukokortikoid
Befruchtung der Eizelle bis zur Bildung der Organanlagen im Embryo stehen. Ab der neunten Schwangerschaftswoche, d.h. nach Abschluss der Organentwicklung, wird der Embryo als Fetus bezeichnet.

primärer Tumor des Zentralnervensystems; entsteht im Ventrikelsystem des Gehirns oder im Rückenmarkskanal. Ependymome machen etwa $10 \%$ aller primären ZNSFTumoren bei Kindern und Jugendlichen aus. Sie sind unterschiedlich bösartig.

Gliazellen, die die Innenwände der Hirnkammern (Hirnventrikel) und des Rückenmarkkanals auskleiden. Sie sind für Produktion, Transport und Abbau der Gehirn-Rückenmark-Flüssigkeit (Liquor) verantwortlich.

Erkrankung, die mit Krampfanfällen einhergeht; sie beruht auf Funktionsstörungen des Gehirns bzw. Entladungsstörungen von Nervenzellen, die durch unterschiedliche Faktoren ausgelöst werden können. Die Behandlung erfolgt in der Regel mit Antiepileptika. Insgesamt werden, je nach Ursache, Elektroenzephalographie-Eigenschaften und klinischem Erscheinungsbild, viele verschiedene Formen von epileptischen Anfällen unterschieden. Sie werden entsprechend unterschiedlich behandelt.

kleiner neurochirurgischer Eingriff, bei dem überschüssige Gehirn-Rückenmark-Flüssigkeit aus den Hirnwasserkammern (Hirnventrikeln) nach außen abgeleitet wird.

der im Kopf gelegene Teil des Zentralnervensystems (ZNS). Das Gehirn liegt geschützt in der Schädelhöhle, wird umhüllt von den Hirnhäuten und besteht hauptsächlich aus Nervengewebe.

Flüssigkeit, die von Zellen der Hirnventrikel gebildet wird. Sie umspült Gehirn und Rückenmark, um diese vor Verletzungen zu schützen und mit Nährstoffen zu versorgen.

Sammelbezeichnung für alle von Gliazellen ausgehenden, vor allem im Gehirn lokalisierten, echten Tumoren des Zentralnervensystems (z.B. Astrozytome, Oligodendrogliome, Glioblastome; Ependymome)

Steroidhormon mit entzündungshemmender Wirkung. Glukokortikoide werden in der Nebennierenrinde gebildet und nach Anregung durch das Hormon Corticotropin (ACTH) aus der 
Grenzstrang

Großhirn

Großhirnrinde

hintere Schädelgrube

Hirnhäute

Hirnstamm

Hirnventrikel
Hirnanhangsdrüse in den Blutkreislauf abgegeben. Sie haben inre Hauptwirkungen im Zucker- und Fettstoffwechsel sowie beim Abbau von Körpereiweißen.

beidseits der Wirbelsäule liegende Kette aus zahlreichen Nervenknoten (Ganglien) des sympathischen Nervensystems; das sympathische Nervensystem ist Teil des autonomen Nervensystems.

größter und am höchsten entwickelter Gehirnabschnitt. Besteht aus zwei Hirnhälften (Hemisphären), die durch ein dickes Nervenbündel (Balken) miteinander verbunden sind. Jede Hirnhälfte ist auf bestimmte Aufgaben spezialisiert. Die äußerste Schicht des Großhirns, die Großhirnrinde, beherbergt u.a. die Lern-, Sprech- und Denkfähigkeit sowie das Bewusstsein und Gedächtnis. Hier liegen auch die Verarbeitungszentren für Informationen aus den Sinnesorganen (z.B. Augen, Ohren).

äußere Schicht des Großhirns; sie ist reich an Nervenzellen und beherbergt u.a. die Lern-, Sprech- und Denkfähigkeit sowie das Bewusstsein und Gedächtnis. Hier liegen auch die Verarbeitungszentren für Informationen aus den Sinnesorganen (z.B. Augen, Ohren).

Teil des knöchernen Schädels, in dem sich unter anderem das Kleinhirn, ein Teil des Hirnstamms (die Rückseite der Brücke = Pons), der 4. Hirnventrikel und der Zusammenfluss der venösen Blutleiter (confluens sinuum) befinden.

Bindegewebsschichten, die das Gehirn schützend umhüllen. An die drei Hirnhäute schließt sich nach außen der Schädelknochen an. Im Bereich des Rückenmarks gehen die Hirnhäute in die ebenfalls dreischichtige Rückenmarkshaut über, die den Rest des Zentralnervensystems umgibt.

Abschnitt des Gehirns, der den Übergang zwischen Gehirn und Rückenmark bildet. Es steuert lebenswichtige Funktionen wie Atmung, Herzfrequenz und Blutdruck und ist für wichtige Reflexe wie z.B. den Lidschluss-, Schluck- oder Hustenreflex, den Tränenfluss und die Speichelproduktion zuständig. Hier liegen auch die Ursprungsorte der Hirnnerven.

mit Gehirn-Rückenmark-Flüssigkeit (Liquor cerebrospinalis) gefüllte Gehirnkammern; die insgesamt vier Hirnventrikel stellen die Fortsetzung des Rückenmarkkanals dar, der sich im Gehirn zu vier Kammern erweitert. 
Hormon

Hypophyse

Hypothalamus

IGF-1

Immunsuppression

Immunsystem

Hormone sind chemische Signalstoffe (Eiweiße), die in unterschiedlichen Körperdrüsen produziert werden und verschiedene Aufgaben haben (zum Beispiel Schilddrüsenhormon, Wachstumshormon, Geschlechtshormone).

Hormondrüse im Schädelinnern; sie spielt gemeinsam mit dem Hypothalamus eine zentrale Rolle bei der Regulation des Hormonsystems im Körper. Die Hypophysenhormone regen die Produktion und Ausschüttung von Hormonen in den verschiedenen Hormondrüsen des Körpers (wie Schilddrüse, Brustdrüsen, Eierstöcke, Hoden) an. Sie steuern dabei z.B. das Längenwachstum vor der Pubertät, fördern das Wachstum der inneren Organe und die Entwicklung der Keimzellen in den Eierstöcken bzw. Hoden und haben Einfluss auf den Stoffwechsel.

Teil des Zwischenhirns und oberstes Steuerungsorgan des Hormonsystems. Der Hypothalamus steuert zahlreiche vegetative Körperfunktionen (z.B. Blutdruck und Herzfrequenz) und ist das übergeordente Zentrum der Homöostase. Er kontrolliert u.a. den Wach-Schlaf-Rhythmus, Hunger und Durst, Körpertemperatur sowie den Sexualtrieb und verarbeitet Schmerz- und Temperaturempfinden. Zudem steuert er die Hirnanhangsdrüse (Hypophyse) und regt sie zur Hormonausschüttung an.

Abk. für Insulinähnlicher Wachstumsfaktor 1 (engl. Insulin-like growth factor 1); körpereigenes Eiweiß, das in seiner Struktur dem Insulin ähnelt und als Wachstumsfaktor wirkt (Wachstum und Differenzierung von Zellen). Es wird hauptsächlich in der Leber nach Stimulation durch das Wachstumshormon Somototropin gebildet und spielt vor allem in der Wachstumsphase des Organismus eine große Rolle.

\section{Unterdrückung der körpereigenen Abwehr}

körpereigenes System zur Erhaltung des gesunden Organismus durch Abwehr körperfremder Substanzen und Vernichtung anomaler Körperzellen (z.B. Krebszellen); das Immunsystem hat die Fähigkeit, zwischen selbst und fremd bzw. gefährlich und harmlos zu unterscheiden; beteiligt sind hauptsächlich die Organe des lymphatischen Systems sowie im ganzen Körper verteilte Zellen (z.B. Leukozyten) und Moleküle (z.B. Immunglobuline).

Indikation

Grund für die Anwendung bestimmter Untersuchungs- und Behandlungsmethoden, die für den jeweiligen Krankheitsfall hinreichend gerechtfertigt sind und für die grundsätzlich Aufklärungspflicht besteht. 
Infektion

Katecholamine

Keimzelltumor

Kleinhirn

Kleinhirnzelt

Leukämie

Liquor
Eindringen kleinster Organismen (z.B. Bakterien, Viren, Pilze) in den Körper und anschließende Vermehrung in diesem. Je nach Eigenschaften der Mikroorganismen und der Abwehrlage des Infizierten kann es nach Infektionen zu verschiedenen Infektionskrankheiten kommen.

Sammelbegriff für die körpereigenen Substanzen Dopamin, Adrenalin und Noradrenalin, die als Botenstoffe (Hormone) des sympathischen Nervensystems eine anregende Wirkung auf das Herz-Kreislauf-System haben (sie führen zu einer Steigerung von Herzfrequenz und Blutdruck). Katecholamine werden in den Nebennieren und im Nervensystem gebildet. Es gibt auch künstlich hergestellte Katecholamine, die als Arzneistoffe verwendet werden.

Keimzelltumoren sind embryonale, solide Tumoren, die aus entarteten Stammzellen und Vorläuferzellen der Keimdrüsen während der Entwicklung des Menschen im Mutterleib oder danach entstehen; sie kommen v.a. im Steißbeinbereich, in den Eierstöcken, den Hoden oder im Zentralnervensystem vor. Am häufigsten sind Keimzelltumoren bei Säuglingen und Kindern bis zum 1. Lebensjahr; sie machen insgesamt $3,4 \%$ aller Krebserkrankungen im Kindes- und Jugendalter aus.

Teil des Gehirns, der zwischen Großhirn und Hirnstamm in der hinteren Schädelgrube liegt; verantwortlich u.a. für den richtigen Ablauf aller Körperbewegungen; außerdem maßgeblich an der Aufrechterhaltung des Gleichgewichts beteiligt.

bindegewebige Struktur, die wie eine Art Zwischenwand die hinteren Anteile des Großhirns vom Kleinhirn abgrenzt und und nur eine Durchtrittsstelle für den Hirnstamm freilässt. Sie wird von der harten Hirnhaut gebildet, die dachartig die hintere Schädelgrube überdeckt.

bösartige Erkrankung des Blut bildenden Systems und häufigste Krebserkrankung bei Kindern und Jugendlichen (mit ca. 33\%); je nach Herkunft der bösartigen Zellen unterscheidet man lymphoblastische und myeloische Leukämien. Abhängig vom Krankheitsverlauf (schnell oder langsam) werden akute und chronische Leukämien unterschieden.

Flüssigkeit; das Wort wird meist für die Gehirn-RückenmarkFlüssigkeit benutzt, die von Zellen der Hirnventrikel gebildet wird. Sie umspült Gehirn und Rückenmark, um diese vor Verletzungen zu schützen und mit Nährstoffen zu versorgen. 
Lumbalpunktion

Lymphom

Magnetresonanztomographie

Medulloblastom

Mittelhirn

Nervengewebe

Nervenzellen

Neuroblastom
Einstich in den Wirbelkanal im Bereich der Lendenwirbelsäule, z.B. zur Entnahme von Gehirn-Rückenmark-Flüssigkeit (Liquor) oder zwecks Verabreichung von Medikamenten (so genannte intrathekale Behandlung), Bei einer Krebserkrankung kann eine Entnahme und Untersuchung von Liquor dem Nachweis bösartiger Zellen dienen; bei erhöhtem Hirndruck aufgrund eines ZNS-Tumors dient die Liquorentnahme ggf. auch einer Druckentlastung.

Sammelbegriff für

Lymphknotenvergrößerungen

unterschiedlicher Ursachen

bildgebendes Verfahren; sehr genaue, strahlenfreie Untersuchungsmethode zur Darstellung von Strukturen im Inneren des Körpers; mit Hilfe magnetischer Felder werden Schnittbilder des Körpers erzeugt, die meist eine sehr gute Beurteilung der Organe und vieler Organveränderungen ermöglichen.

bösartiger embryonaler (primitiver) Tumor des Kleinhirns. Er tritt vor allem im Kleinkindes- und Kindesalter auf und ist mit knapp $20 \%$ der häufigste bösartige solide Tumor im Kindes- und Jugendalter.

Teil des Hirnstamms; grenzt nach oben an das Zwischenhirn an, nach unten an die Brücke, die ebenfalls zum Hirnstamm gehört. Im Mittelhirn verlaufen wichtige, zwischen Gehirn und Rückenmark auf- und absteigende Bahnen. Im Mittelhirn befinden sich auch die Ursprungsorte für die Augenmuskelnerven (Hirnnerven III und IV) sowie die Nervenzellkerne für bestimmte Muskelaktivitäten.

Gewebe des Nervensystems; es besteht aus Nervenzellen (Neuronen) und einem eigenen, speziellen Bindegewebe, den Gliazellen.

Bestandteile des Nervensystems höherer Lebewesen, die hauptsächlich für die Nachrichten-Übertragung im Organismus zuständig sind (durch Weiterleitung, Verarbeitung und Empfang von Signalen) Mit ihren Fortsätzen und den Synapsen bilden die Nervenzellen ein Netzwerk, durch das wichtige Signale weitergegeben und unwichtige Signale unterdrückt werden.

bösartiger solider Tumor des sympathischen Nervensystems; tritt gehäuft vor dem 5. Lebensjahr und vor allem bei Säuglingen und Neugeborenen auf und ist mit einem Anteil von etwa $8 \%$ aller bösartigen Erkrankungen der zweithäufigste solide 
Neurochirurg

Neurofibromatose

neurologisch

Neurotransmitter

niedriggradig maligne

Gliome

niedrigmaligne Gliome
Tumor im Kindes- und Jugendalter (nach den Tumoren des Zentralnervensystems)

Facharzt, der u.a. für die Erkennung und operative Behandlung von Erkrankungen, Fehlbildungen und Verletzungen des Nervensystems (Zentralnervensystem und peripheres Nervensystem) zuständig ist.

erbliche Erkrankung, die zu Tumoren der Nervenscheiden, der Hirnhäute und der Glia (dem "Bindegewebe" des Nervensystems) führen. Klinisch und molekulargenetisch lassen sich zwei Formen der Neurofibromatose unterscheiden, die durch unterschiedliche genetische Defekte hervorgerufen werden: 1. Die periphere Neurofibromatose (NF1, auch Recklinghausen-Krankheit): diese ist durch so genannte Cafe-au-lait-Flecken auf der Haut und eine Veranlagung für verschiedene Tumoren gekennzeichnet (u.a. Neurofibrome, Gliome des Sehnervs, Irishamartome sowie Astrozytome und Phäochromozytome). 2. Die zentrale Neurofibromatose (NF2): sie ist durch meist (beidseitige) Neurinome des Hörnervs (Acusticus) charakterisiert, die zu Taubheit, Gesichtslähmungen und geistigen Störungen führen können. Die Neurofibromatose gehört zu den so genannten Phakomatosen.

die Funktion des Nervensystems/Nervengewebes betreffend

biochemische Substanzen, die Informationen zwischen Nervenzellen über die Kontaktstellen der Nervenzellen (Synapsen) weiterleiten. Die elektrischen Impulse, die in die Synapse einlaufen, veranlassen die Ausschüttung der chemischen Botenstoffe aus ihren Speicherorten, den synaptischen Vesikeln.

geringgradig bösartige Tumoren des Zentralnervensystems, mit 30 bis $40 \%$ die größte Gruppe der ZNSFTumoren bei Kindern und Jugendlichen. Niedrigmaligne Gliome kommen am häufigsten im Kleinhirn'und in den zentralen Anteilen des Großhirn's vor. Zu den niedrigmalignen Gliomen zählen zum Beispiel Astrozytome, Gangliogliome und Oligodendrogliome (WHO-Grad I-II).

geringgradig bösartige Tumoren des Zentralnervensystems, mit 30 bis $40 \%$ die größte Gruppe der ZNSFTumoren bei Kindern und Jugendlichen. Niedrigmaligne Gliome kommen am häufigsten im Kleinhirn` und in den zentralen Anteilen des Großhirn's vor. Zu den niedrigmalignen Gliomen zählen zum Beispiel Astrozytome, Gangliogliome und Oligodendrogliome (WHO-Grad I-II). 
Noradrenalin

Nystagmus

Ödem

Operation

Osteosarkom

parasympathisches

Nervensystem

peripheres Nervensystem
Körpereigener Botenstoff des Nervensystems (Neurotransmitter) und Hormon; wird von bestimmten Nervenzellen und im Nebennierenmark gebildet. Die wichtigste Funktion von Noradrenalin ist seine Rolle als Neurotransmitter in Zentralnervensystem und sympathischem Nervensystem. Als Hormon des Nebennierenmarks wirkt es stark gefäßverengend und blutdruckerhöhend. Noradrenalin gehört zur Stoffgruppe der Katecholamine.

unwillkürliche, rhythmische Augenbewegungen; „Augenzittern“

(meist) schmerzlose, nicht gerötete Schwellung infolge Ansammlung von Flüssigkeit aus dem Blut in unterschiedlichen Körperregionen

chirurgischer Eingriff am oder im Körper eines Patienten zwecks Behandlung, seltener auch im Rahmen der Diagnostik; der chirurgische Eingriff erfolgt mit Hilfe spezieller Instrumente, im Allgemeinen unter Narkose.

Häufigster Knochentumor im Kindes- und Jugendalter; tritt v.a. in der zweiten Lebensdekade während der pubertären Wachstumsphase auf

Teil des vegetativen (autonomen) Nervensystems. Der Parasympathicus dient hauptsächlich der Wiederherstellung der körperlichen Energien in Phasen der Ruhe und Erholung. Seine Erregung führt zu einer Verstärkung der Magen-Darm-Tätigkeit, zur Förderung der Blasen- und Mastdarmfunktion, zur Verlangsamung von Herzschlag und Atmung und zu einer Pupillenverengung. Gegenspieler des parasympathischen Nervensystems ist das sympathische Nervensystem (Sympathicus)

kann als Empfangs- und Ausführungsorgan des Zentralnervensystems (ZNS) bezeichnet werden. Es besteht aus den zahlreichen Nerven, die den Körper durchziehen; sie tragen entweder Impulse von der Peripherie zum ZNS (sensible Nervenbahnen) oder vom ZNS in die Peripherie (motorische Nervenbahnen). Zum peripheren Nervensystem gehören zum Beispiel die Hirnnerven, Rückenmarksnerven und die peripheren Nervenzellen.

Vorhersage, Voraussicht auf den Krankheitsverlauf, Heilungsaussicht 
Retinoblastom

Rückenmark

Sehnerv

Shunt

Steroidhormon

Strahlentherapie

sympathisches

Nervensystem
Bösartiger Tumor der Augen-Netzhaut (Retina), der fast ausschließlich bei Kindern auftritt. Insgesamt kommt das Retinoblastom im Kindes- und Jugendalter - mit $2 \%$ aller Krebserkrankungen - selten vor. Es gibt erbliche und nicht-erbliche Formen der Erkrankung. Sowohl ein als auch beide Augen können betroffen sein.

Teil des Zentralnervensystems; seine Hauptaufgabe ist die Nachrichtenvermittlung zwischen Gehirn und anderen Körperorganen. Das Rückenmark wird von den drei Rückenmarkshäuten und dem knöchernen Wirbelkanal schützend umhüllt.

erster Abschnitt der Sehbahn, die von der Augen-Netzhaut (Retina) ausgeht und bis in das Sehzentrum der Großhirnrinde führt. Der Sehnerv besteht aus den Fortsätzen (Axonen) der Nervenzellen der Netzhaut und enthält damit insgesamt rund eine Million Nervenfasern. Der durchschnittlich 4,5 cm lange Sehnerv lässt sich in drei Teile gliedern: einen im Augapfel, einen in der Augenhöhle und einen im Schädel gelegenen Teil.

"Shunt" ist Englisch bedeutet im allgemeinen "Verbindung". Der Begriff wird in vielen verschiedenen Bereichen der Medizin benutzt, hauptsächlich für eine chirurgisch hergestellte Verbindung zwischen zwei Organsystemen. Außerdem wird eine Verbindung zwischen dem venösen und dem arteriellen Blutkreislauf (z. B. bei manchen angeborenen Herzfehlern) als (arteriovenöser) Shunt bezeichnet.

Steroide, die als Hormone wirken; zu den Steroidhormonen gehören z.B. die Kortikosteroide der Nebennierenrinde und die Sexualhormone der Keimdrüsen (Eierstöcke und Hoden). Das Ausgangsprodukt der Steroidhormone ist das Cholesterin. Insgesamt werden sechs Gruppen unterschieden: Glucocortidoide, Mineralocorticoide, Androgene, Östrogene, Gestagene und Vitamin D. Steroidhormone sind gut fettlöslich und können daher direkt in die Zelle gelangen, wo sie an ihre Rezeptoren binden. Der Steroid-Rezeptor-Komplex gelangt dann in den Zellkern und kann dort, durch Wechselwirkung mit der DNA, auf den Stoffwechsel der Zelle Einfluss nehmen.

kontrollierte Anwendung ionisierender (hochenergetischer) Strahlen zur Behandlung von bösartigen Erkrankungen

Teil des vegetativen (autonomen) Nervensystems und Gegenspieler des parasympathischen Nervensystems 
Synapse

Thalamus

Thyroxin

undifferenziert

UV-Strahlen

Varizella-Zoster-Virus

vegetatives Nervensystem
(Parasympathicus). Der Sympathicus dient der Anpassung an Anforderungs- und Stresssituationen. Seine Erregung führt zum Beispiel zu einer Erhöhung des Blutdrucks, einer Beschleunigung von Herzschlag und Atmung, einer Erweiterung der Pupillen und einer erhöhten Schweißabsonderung, während die Tätigkeiten von Magen und Darm und deren Drüsen gleichzeitig gedämpft werden.

Kontaktstelle zwischen zwei Nervenzellen oder zwischen einer Nervenzelle und einer anderen Zelle, z.B. einer Sinnes-, Muskel- oder Drüsenzelle. An dieser Stelle findet die Erregungsübertragung (und somit Signalweiterleitung) von einer Zelle (Neuron) zur anderen statt.

Teil des Zwischenhirns. Hier enden die Bahnen für verschiedene Gefühlsempfindungen. Der Thalamus ist durch auf- und absteigende Nervenfaserbahnen mit anderen Hirnabschnitten (Kleinhirn, Hirnstamm, Großhirnrinde) verbunden.

Hormon der Schilddrüse; dient als Vorläuferhormon (Vorstufe) für T3 (Trijodthyronin). Die Schilddrüsenhormone T3 und T4 erhöhen, wenn sie ins Blut freigesetzt werden, u.a. den Energieumsatz des menschlichen Körpers und passen inn somit an Kälte und Aktivität an.

hier: unreif, noch nicht funktionstüchtig und i.d.R. unbegrenzt teilungsfähig (Beispiel Stammzellen). Die Entwicklung von undifferenzierten zu differenzierten Zellen und Geweben (Differenzierung) erfolgt schrittweise. Entsprechend gibt es viele verschiedene Differenzierungsgrade.

für Menschen unsichtbare, kurzwellige elektromagnetische Strahlung. Sie hat biologisch und medizinisch eine große Bedeutung, da ihre Energie imstande ist, biochemische Veränderungen in Zellen und somit Zellschäden hervorzurufen. Die Wellenlänge der Ultraviolett-Strahlung ist kürzer als die des sichtbaren Lichtes. Als ulttraviolett wird sie bezeichnet, weil sie sich an den blauvioletten Bereich des sichtbaren Lichtes anschließt.

DNS-Virus aus der Familie der Herpesviren; Erreger der Windpocken (Varizellen) und der Gürtelrose (Zoster); Übertragung durch Tröpfchen- und Schmierinfektion

Teil des Nervensystems; setzt sich aus zwei Anteilen, dem Sympathicus und dem Parasymphaticus, zusammen und dient 
Vene

venös

ventrikulo-peritonealer

Shunt

Ventrikulostomie

Wasserkopf

Weichteilsarkome

Zellkern

Zentralnervensystem der unbewussten und unwillkürlichen (d.h. der vom Willen weitgehend unabhängigen) Steuerung der inneren Organe und damit zahlreicher lebenswichtiger Vorgänge, zum Beispiel Atmung, Verdauung, Blutdruckregulation, und Wasserhaushalt. Nervenfasern des vegetativen Nervensystems gibt es in fast allen Körperorganen.

Blutader; nicht pulsierendes Blutgefäß mit zum Herzen führender Strömungsrichtung des Blutes; führt i.d.R. sauerstoffarmes (verbrauchtes) Blut von den Organen zum Herzen hin, nur die Lungenvenen haben sauerstoffreiches Blut

zu den Venen (zum Herzen hinführende Blutgefäße) gehörig

Shunt $(=$ Schlauchsystem mit Ventil) zur Ableitung überschüssiger Gehirn-Rückenmark-Flüssigkeit (Liquor) aus den Hirnwasserkammern (Hirnventrikel) in die Bauchhöhle (Peritoneum).

Neurochirurgischer Eingriff zur Wiederherstellung des Nervenwasserflusses, z. B. bei einem Wasserkopf (Hydrocephalus). Dabei wird eine (mit Hilfe eines Endoskops) kontrollierte künstliche Verbindung am Boden des dritten Hirnventrikels nach außen in den Rückenmarkskanal geschaffen und somit die Ableitung von überschüssiger Gehirn-RückenmarkFlüssigkeit (Liquor) ermöglicht.

Erweiterung der Flüssigkeitsräume des Gehirns (Hirnventrikel) aufgrund verschiedener Ursachen

Vielzahl sehr verschiedener bösartiger Erkrankungen, die von Weichgeweben - zum Beispiel Binde-, Fett- und Muskelgewebe oder Gewebe der peripheren Nerven - ausgehen; machen knapp $7 \%$ der bösartigen Erkrankungen im Kindes- und Jugendalter aus; häufigstes Weichteilsarkom bei Kindern und Jugendlichen ist das Rhabdomyosarkom.

Bestandteil der Zelle, der die Chromosomen, also die Träger der Erbinformation (Gene) enthält; stellt das Steuerzentrum der Zelle dar.

umfasst Gehirn und Rückenmark und wird vom so genannten peripheren Nervensystem abgegrenzt; als zentrales Integrations-, Koordinations- und Regulationsorgan dient es der Verarbeitung von äußeren Sinneseindrücken sowie von Reizen, die vom Organismus selbst produziert werden. 
Zirbeldrüse

ZNS-Tumor

Zwischenhirn

Zytostatikum
Hormondrüse, die zwischen den beiden Großhirnhälften am Zwischenhirn befestigt ist. Ihre Funktion besteht wahrscheinlich in der Bildung von Melatonin, einem Hormon, das auf die Veränderung von Lichtverhältnissen reagiert.

Tumor des Zentralnervensystems; Ein primärer ZNS-Tumor ist ein solider Tumor, der in Gehirn- oder Rückenmarksgewebe entsteht. Bei sekundären ZNS-Tumoren handelt es sich um Metastasen von Tumoren anderer Organe oder Gewebe.

lebenswichtiger Teil des Gehirns mit Funktion für zahlreiche Lebensvorgänge; schließt sich an den Hirnstamm in Richtung Großhirn an und besteht aus funktionell unterschiedlichen Abschnitten. Der "Thalamus" z.B. entscheidet, welche Sinneseindrücke ins Bewusstsein dringen sollen und leitet sie an die entsprechenden Verarbeitungszentren weiter. Der "Hypothalamus" dient als Vermittler zwischen Hormon- und Nervensystem und steuert u.a. wichtige Stoffwechselvorgänge (z.B. Wärme-, Wasserhaushalt, Kohlenhydrat-, Fett-, Proteinstoffwechsel, Blutdruck). Mit der Hirnanhangsdrüse, der Hypophyse, reguliert er die Aktivität untergeordneter Drüsen. Andere Teile des Zwischenhirns sind z.B. für Muskelaktivitäten und für die Steuerung des Tag-Nacht-Rhythmus mit verantwortlich.

zellwachstumshemmendes Medikament; kann verschiedenartige, insbesondere sich häufig teilende Zellen durch Beeinflussung ihres Stoffwechsels vernichten und/oder deren Vermehrung verhindern oder erheblich verzögern 